\title{
Not-in-kind cooling technologies: a quantitative comparison of refrigerants and system performance
}

\author{
Suxin Qian ${ }^{\mathrm{a}}$, Dennis Nasuta ${ }^{\mathrm{b}}$, Adam Rhoads ${ }^{\mathrm{b}}$, Yi Wang ${ }^{\mathrm{c}}$, Yunlong Geng ${ }^{\mathrm{c}}$, Yunho Hwang ${ }^{\mathrm{a}}$, \\ Reinhard Radermacher ${ }^{\mathrm{a}, \mathrm{b}}$, Ichiro Takeuchi $^{\mathrm{c}}$ \\ ${ }^{a}$ Center for Environmental Energy Engineering, Department of Mechanical Engineering, \\ University of Maryland, 4164 Glenn L. Martin Hall Bldg., College Park, MD 20742, USA \\ ${ }^{\mathrm{b}}$ Optimized Thermal Systems, Inc., 5000 College Park Avenue, Suite 3105, College Park, MD \\ 20740, USA
}

${ }^{c}$ Department of Material Science and Engineering, University of Maryland, 1242 Jeong H. Kim Engineering Building, College Park, MD 20742, USA

*Corresponding Author

Tel: (+1) 301-405-5247, Fax: (+1) 301-405-2025, Email: yhhwang@umd.edu

\begin{abstract}
With advances in solid-state cooling materials in the past decade, non-vapor compression technologies, or not-in-kind (NIK) cooling technologies have garnered great attention. Therefore, a universal performance index is urgently needed to compare these NIK technologies with each other and vapor compression cooling as well. In this study, a systematic method is developed to visualize the contributions to the coefficient of performance (COP) from materials (working fluids) level to the system level as a function of temperature lifts. Since the materials level COP depends solely on the materials properties under the specified cycle, it can be used for comparing refrigerants for all NIK technologies. We chose the water-cooled water chiller operating under identical conditions as the basis for the system performance comparison of all NIK cooling


technologies. Upon normalizing the system COP to the Carnot COP, its variation with the system temperature lift reveals the intrinsic potential applications for each NIK cooling technology.

Keywords: magnetocaloric, elastocaloric, thermoelectric, Stirling, electrocaloric, vapor compression

\section{Nomenclature}

A

AMR

CFCs

COP

$c_{p}$

D

E

HCFCs

HVAC

$H$

$h$

I

$k$

$L$

$l$

$\Delta m$

NIK

$p$

$P$ materials constant related to hysteresis $\left[\mathrm{J} \cdot \mathrm{g}^{-1}\right]$

active magnetic regenerator

chlorofluorocarbons

coefficient of performance [-]

specific heat $\left[\mathrm{J} \cdot \mathrm{g}^{-1} \cdot \mathrm{K}^{-1}\right]$

electric displacement $\left[\mathrm{C} \cdot \mathrm{m}^{-2}\right]$

electric field intensity $\left[\mathrm{N} \cdot \mathrm{C}^{-1}\right]$

hydrochlorofluorocarbons

heating, ventilating, and air-conditioning

magnetic field $\left[\mathrm{A} \cdot \mathrm{m}^{-1}\right]$

specific enthalpy $\left[\mathrm{J} \cdot \mathrm{g}^{-1}\right]$

current $[\mathrm{A}]$

thermal conductivity $\left[\mathrm{W} \cdot \mathrm{m}^{-1} \cdot \mathrm{K}^{-1}\right.$ ]

latent heat $\left[\mathrm{J} \cdot \mathrm{g}^{-1}\right]$

length [m]

magnetic moment change $\left[\mathrm{A} \cdot \mathrm{m}^{2} \cdot \mathrm{kg}^{-1}\right]$

not-in-kind

pressure $[\mathrm{MPa}]$

polarization $\left[\mathrm{C} \cdot \mathrm{m}^{-2}\right]$ 
capacity per unit mass $\left[\mathrm{J} \cdot \mathrm{g}^{-1}\right]$

relative cooling power $\left[\mathrm{J} \cdot \mathrm{g}^{-1}\right]$

shape memory alloys

specific entropy $\left[\mathrm{J} \cdot \mathrm{g}^{-1} \cdot \mathrm{K}^{-1}\right]$

temperature $[\mathrm{K}]$

cold side (heat source) temperature for a heat pump [K]

hot side (heat sink) temperature for a heat pump [K]

specific volume $\left[\mathrm{m}^{3} \cdot \mathrm{kg}^{-1}\right]$

work per unit mass $\left[\mathrm{J} \cdot \mathrm{g}^{-1}\right]$

length $[\mathrm{m}]$

thermoelectric materials figure-of-merit $\left[\mathrm{K}^{-1}\right]$

Seebeck coefficient $\left[\mathrm{V} \cdot \mathrm{K}^{-1}\right]$

strain [-]

resistivity $[\Omega \cdot \mathrm{m}]$

non-dimensional latent heat [-]

uniaxial stress [MPa]

magnetic field [Tesla, or T]

normalized materials level $C O P$, or materials exergetic efficiency [-] system exergetic efficiency (normalized to materials $C O P$ ) [-]

system temperature lift $[\mathrm{K}]$

heat exchanger approach temperature $[\mathrm{K}]$

\section{Introduction}

Vapor compression cooling systems are operated as reverse Rankine cycle while utilizing refrigerant liquid-vapor phase change, and they dominate use in heat pumps, air-conditioners and refrigerators around the world. The term of not-in-kind (NIK) cooling technologies refers to any 
alternative cooling systems other than the vapor compression cooling systems that are most commercially dominant today. As indicated by Figure 1, different materials may be used, such as solid-state materials (shape memory alloys, magnetic materials and ferroelectric materials), gases (air) and even liquids. Even the liquid-vapor phase change materials themselves can be applied in a variety of different cycles. For example, absorption/adsorption cooling uses the heat to drive the cycle instead of compressors in vapor compression systems.

Pursuit of NIK cooling/heating technologies has a long history. When the heating-ventilatingand-air-conditioning (HVAC) industry were seeking for alternatives to the chlorofluorocarbons (CFCs) and hydrochlorofluorocarbons (HCFCs) regulated by the Montreal Protocol, Fischer et al. (1994) comprehensively summarized twelve NIK technologies and concluded that no NIK technologies could replace vapor compression systems in the near future. Nevertheless, niche markets can be expanded, and some heat activated heat pumps have benefit over vapor compression heat pumps in space heating. The carbon dioxide emission was used as an index to quantify the environmental contributions of technologies compared. A few years later, by comparing twenty NIK technologies especially considering cost, Fischer et al. (2000) further emphasized the opportunities for gas-fired heat pumps. It was also stated that advances in materials developments were necessary to bring down the cost and to enhance the performance to make other NIK technologies (especially magnetocaloric cooling and metal hydride heat pumps) more competitive and attractive to commercial applications. Energy conversion efficiency, or COP under different standard conditions was used for comparison. With the rapid development in the next ten years, some of these NIK technologies have undergone significant breakthrough. Magnetocaloric cooling itself had over 200 publications per year in 2007 (Gschneidner and Pecharsky, 2008). Thermoelectric cooling has been commercially available in a few niche markets, such as transportation, electronic cooling, small scale refrigerators and integration to other cooling systems (Zhao and Tan, 2014). Brown et al. (2010) first recognized magnetocaloric 
cooling as having a good prospect for competing with vapor compression systems. Bansal et al. (2011) reviewed the NIK technologies as well as the latest advances in traditional vapor compression cooling technology from the viewpoint of energy efficiency improvement for household appliances, and also stressed the potential of both the magnetocaloric cooling and the thermoelectric cooling. Bansal et al. (2012) further summarized a few more candidates in the NIK list, and highlighted the significance of materials advances in these NIK technologies. Energy efficiency, R\&D status and technical maturity were used as three qualitative comparison indices to compare various NIK technologies. Herms and Barbosa (2012) compared three portable coolers using NIK cooling technologies. Goetzler et al. $(2012,2014)$ prepared two comprehensive reports using a quantitative score considering the energy saving potential, cost/complexity, nonenergy benefit and other aspects to compare the NIK technologies. Elastocaloric cooling (or thermoelastic cooling), membrane cooling and magnetocaloric cooling were considered as high potential alternatives to the vapor compression cooling. Even though a quantitative comparison was used by Goetzler et al., their two studies were still based on rough system performance projections and other qualitative metrics with high uncertainties. Recently, Brown and Domanski (2014) proposed using the exergetic efficiency, or a normalized COP to the COP of Carnot cycle under the exactly same operating temperatures, to quantitatively compare the NIK cooling technologies. Although only the thermal performance was considered, this was the first detailed and fair endeavor to compare the NIK cooling technologies. Unfortunately, the comparison was not quite accurate because some COPs for most early stage developing NIK technologies used were based on a projection of the materials properties only and therefore, were not informative when compared to other pre-established NIK technologies. In addition, as is demonstrated in this study, the exergetic efficiency varies significantly under different temperature lifts, and therefore the comparison should be made under identical conditions. When considering the fact that the efficiency for different cooling technologies might have been reported under completely different operating conditions (air cooled, water cooled, heat source and sink temperatures, temperature 
lift), and whether the parasitic power (pumps, valves, fan motor, cooling tower, etc.) was accounted for in the reported efficiency was not always clear as well, the energy saving potential of the NIK cooling technologies might be misjudged significantly. As the demand for NIK cooling technologies started to attract more attention recently, especially with the advent of novel solid-state cooling technologies (Cui et al., 2012, Jacobs et al., 2014, Gu et al., 2013), a fair comparison based on the same ground is needed to guide development of these NIK cooling technologies. Therefore, the objective of this study is to develop such a standardized comparison basis for the research community and future studies. An additional freedom is added to the proposed method by Brown and Domanski (2014), which is the detailed COP (exergetic efficiency) breakdown chart as shown in Figure 2 (Qian et al., 2015b). With the breakdown chart, the materials level COP (only dependent on materials properties and the cycle path) represents the theoretical limit for a certain NIK cooling technology assuming that the system is fully reversible, which is 15.5 for a Ni-Ti shape memory alloy under the Stirling cycle in Figure 2 at 10 K temperature lift. Materials advances in the future will extend this limit. System limitations add more irreversibilities, which are shown in Figure 2 as adiabatic compression losses due to the Brayton cycle operation, motor efficiency, heat transfer irreversibility and parasitic power, respectively. The bottom level $C O P$ represents the system level $C O P$ under the given operating conditions. With the additional freedom, comparison at the materials level COPs among different NIK technologies determines the theoretical limit for each technology, and comparing system level $C O P$ s leads to comparison of system integration perfectiveness. These two level COPs and the normalized exergetic efficiencies are correlated and defined in Eqs. (1-2). The Carnot COP is defined in Eq. (3) as well. In this study, the same terminology used by Brown and Domanski (2014) was used. $\Phi_{\text {mat }}$ is the normalized materials $C O P$, or the materials level exergetic efficiency. $\Phi_{\text {sys }}$ is a measure of the perfectness of the system integration. $\Phi_{\text {sys }}$ equals one does not mean the system can reach the Carnot $C O P$, but instead it indicates that all irreversibilities are results from 
the materials themselves. It should also be mentioned that the exact identical exergetic efficiency term used by Herms and Barbosa (2012) was represented as $\eta_{\mathrm{s}}$.

$$
\begin{aligned}
& C O P_{\text {mat }}=C O P_{\text {carnot }} \Phi_{\text {mat }} \\
& C O P_{\text {system }}=C O P_{\text {carnot }} \Phi_{\text {mat }} \Phi_{\text {sys }} \\
& C O P_{\text {Carnot }}=\frac{T_{c}}{\Delta T_{\text {lift }}} \equiv \frac{T_{c}}{T_{h}-T_{c}}
\end{aligned}
$$

The second added freedom is the temperature lift. Extending the temperature lift of $10 \mathrm{~K}$ used in Figure 2 reveals how these technologies would perform for different applications, i.e. small temperature lift coolers, medium temperature lift air-conditioners, and large temperature lift refrigerator/freezers.

It should be noted that Eq. (3) implies that the so-called external Carnot COP was used with the external environmental temperature $T_{\mathrm{c}}$ and $T_{\mathrm{h}}$, instead of the cycle's internal high side and low side temperatures. This difference was highlighted and used by Herms and Barbosa (2012) first and then applied by Brown and Domanski (2014). Both Herms and Barbosa (2012) and Brown and Domanski (2014) used the same metric in Eq. (2), normalizing the system overall COP to the Carnot COP. The approach proposed by this study added more information by adding two dimensions. By adding different losses from different stages as illustrated by Figure 2, the direction to minimize the most significant loss can be clarified. Especially the material COP in Eq. (1) can be used as a simple comparison index to compare the ultimate potential of each NIK cooling technologies, when the system level degradation factors would have been eliminated. The second dimension, temperature lift, extended the comparison by varying the operating conditions, to determine the most efficient application for each NIK cooling technology.

Despite the diversity of refrigerants/materials, work input energy conversion principles and systems configuration of the various NIK cooling technologies, there are some universal common 
features that all cooling technologies share. Figure 3 demonstrates these features by using a vapor compression system as an example. The material/refrigerant is the core of all cooling systems, which convert the input work into cooling and heating. To enable the energy conversion process, a work input interface is needed, which can be a compressor for gas, a compression machine for shape memory alloys, a permanent magnet for magnetocaloric materials, or an electric field for electrocaloric materials. The heat transfer interface absorbs cooling load and rejects heat into ambient. For a vapor compression air-conditioner, the external fluid is air and the heat transfer interfaces are the refrigerant-air heat exchangers. In this study, the comparison application is water chiller, and therefore water heat exchangers are the heat transfer interface. It is important that the comparison basis is identical for all NIK cooling technologies, which means that the specific external fluid conditions are identical for all compared NIK cooling technologies in this study. The fluid temperatures $T_{\mathrm{c}}$ and $T_{\mathrm{h}}$ in Figure 3 are consistent with those in Eq. (3). The heat recovery device is to enhance the operating performance by precooling the refrigerant before the cooling process and preheating the refrigerant before the heat rejection process. The system performance can be further improved by applying the work recovery concept, since part of the work can be recovered to reduce the net work input. The last feature was often neglected, especially for NIK cooling technologies. The parasitic power consumption by water pumps, air fans and cooling tower fans are not trivial when compared with the main work input power consumption, especially for those high efficient cooling systems. The heat recovery methods and work recovery methods for various NIK cooling technologies are summarized in Table 1.

Relevant information from literature has been summarized in Table 1 for those NIK technologies in this study. The listed refrigerant/materials are the most common ones for the NIK technologies, and are selected for calculation in this study. The work input form indicates the energy conversion form for each cooling technologies. For example, $p-v$ diagram for vapor refrigerant is required to compute the work where gaseous refrigerant is compressed, and $\sigma-\varepsilon$ diagram should 
be used for elastocaloric cooling where solid-state shape memory alloys are loaded. Only work input driven cooling technologies are compared in this study. Heat driven cycles is beyond current scope. Most systems require heat recovery or regeneration to operate efficiently. Examples of possible heat recovery methods used in literature are summarized in Table 1 as well. A counter-flow heat exchanger between the cold refrigerant and the hot refrigerant is commonly used for steady state operating cycle, i.e. vapor compression and Brayton cycle. Cyclic operating systems require a regenerator, such as Stirling cycle, magnetocaloric cooling and electrocaloric cooling, to cyclically store and release energy to the refrigerant. A separate heat recovery process can be also used for cyclic operating systems, such as elastocaloric cooling.

\section{Comparison of Refrigerant}

There are many quantities used as indices to compare the materials/refrigerants. Since the thermal performance and their potential energy conversion efficiency are the main focus of this study, we have elected to apply the following two indices.

- Non-dimensional latent heat $\gamma$

This is a normalized latent heat as described in Eq. (4) (Qian et al., 2015a). It represents the maximum useful latent heat to the parasitic heat loss ratio. The numerator is the specific latent heat of the material, i.e. evaporation heat for liquid refrigerant in vapor compression system, martensitic phase change latent heat in elastocaloric cooling, or the heat associated with the field induced entropy change for magnetocaloric cooling. The denominator is the parasitic sensible heat loss consumed by the material/refrigerant itself inside the heat pump to change temperature between the hot side (heat sink at $T_{\mathrm{h}}$ ) and the cold side (heat source at $T_{\mathrm{c}}$ ). For thermoelectric cooling, this term is the parasitic heat loss by conduction from the hot side to the cold side. Therefore, when the ratio is above 1 , it means that the material is able to provide useful cooling in a system under the required temperature lift. Otherwise, the cycle 
would not produce useful cooling unless the heat recovery/regenerator cascaded cycle is applied. Details of the following equations are derived in the Appendix. The specific heat $c_{\mathrm{p}}$ used in Eqs. (4 - 11) is the specific heat measured in the low entropy phase, i.e. liquid, martensite, or magnetized state.

$\gamma=\frac{L}{c_{p} \Delta T_{l i f t}}$

$\gamma_{V C C}=\frac{\left(h_{1}-h_{4}\right)_{T}}{c_{p} \Delta T_{l i f t}}$

$\gamma_{\text {thermoelastic }}=\frac{T_{c} \Delta s}{c_{p} \Delta T_{\text {lift }}}$

$\gamma_{\text {magnetocaloric }}=\frac{T_{c} \Delta s\left(T_{c}\right)}{c_{p} \Delta T_{\text {lift }}}$

$\gamma_{\text {electrocaloric }}=\frac{T_{c} \Delta s\left(T_{c}\right)}{c_{p} \Delta T_{l i f t}}$

$\gamma_{\text {thermoelectric }}=\frac{\alpha I_{o p t} T_{c}}{k x \Delta T_{l i f t}}=\frac{\alpha^{2} T_{c}}{k \rho_{e}\left(\sqrt{1+Z T_{m}}-1\right)}=\frac{Z T_{c}}{\left(\sqrt{1+Z T_{m}}-1\right)}$

$\gamma_{\text {Brayton }}=\frac{h_{6}-h_{5}}{c_{p} \Delta T_{\text {lift }}}$

$\gamma_{\text {Stirling }}=\frac{T_{c} \Delta s\left(T_{c}\right)}{c_{p} \Delta T_{\text {lift }}}$

- $\quad C O P$ based on material properties (Material $C O P, C O P_{\text {mat }}$ )

The first index considers only the latent heat without any information about energy conversion efficiency, which depends on both the operating temperatures and the loading process for different technologies (adding magnetic or electric field, or applying mechanical stress) because work and heat are path dependent variables not state variables (Moran et al., 
2011). Therefore, the energy conversion efficiency, $C O P_{\text {mat }}$, as defined in Eq. (12), was a natural extension from the work by Cui et al., (2012), Moya et al. (2015) and Defay et al. (2013), by using only the materials properties under the pre-defined cycle paths. The $C O P_{\text {mat }}$ does not include the system details such as limitations in driving system (compressor, or motor) efficiency, system dynamics, regenerator effectiveness, heat or mass transfer and component geometries. This index can also be converted to the exergetic efficiency in a way similar to Brown and Domanski (2014). It can be regarded as the limit or the maximum potential the material has for each cooling technology. A lower value of $C O P_{\text {mat }}$ means a certain cooling technology has more irreversibility fundamentally in its working principle.

As indicated by Eq. (12), calculation of $C O P_{\text {mat }}$ requires knowledge on the work/power input, which is path dependent in most cases. This path dependency suggests more information is needed beyond Eq. (12), such as the equations-of-states for vapor-liquid refrigerants, or the constitutive equation for SMAs in an elastocaloric cooling system. When using the equationsof-state, the $C O P_{\text {mat }}$ can be determined only based on state variables and materials properties. The detailed equations for the evaluated NIK cooling technologies are shown in Eqs. (13-19). Vapor compression cycle $C O P_{\text {mat }}$ neglecting all system losses can be found in text books for example Radermacher and Hwang (2005), and the cycle diagram is also shown in Figure 4(a). The hysteresis in Figure 4(a) corresponds to the additional pressure needed to induce condensation, as well as the additional vacuum to nucleate bubbles based on the Laplace equation (Carey, V.P., 2008). Elastocaloric cooling cycle $C O P_{\text {mat }}$ has been reported by Qian et al. (2015b) and is shown in Figure 4(b) and Figure 4(c). Note here $A$ is the material constant used in the martensitic phase change phenomenological model describing the martensitic phase change hysteresis. Magnetocaloric $C O P_{\text {mat }}$ was also derived based on the thermodynamics of magnetocaloric effect using Ericsson cycle (Kitanovski and Egolf, 2006) in Figure 4(d) and Figure 4(e), and considering the magnetization hysteresis using a 
parameter $A_{\text {magnetic }}$ A similar method was applied for electrocaloric cooling operated under Ericsson cycle (Ozbolt et al., 2014), where the hysteresis stands for the polarization hysteresis when applying the electric field for electrocaloric materials. Thermoelectric $C O P_{\text {mat }}$ was well developed as a simplified system model and have been used in the past studies quite often (Riffat and Ma, 2004). Standard Brayton and Stirling cycles using ideal gas were available in a book by Moran et al. (2011). Details can be found in the Appendix.

$$
C O P_{\text {mat }}=\frac{q_{c}}{w_{n e t}}
$$

$C O P_{\text {mat }, V C C}=\frac{q_{c}}{w_{\text {compressor }}-w_{\text {expander }}}=\frac{\left(h_{1}-h_{4}\right)_{T}}{\left[\left(h_{2}-h_{1}\right)_{s}-\left(h_{3}-h_{4}\right)_{s}\right]}$

$C O P_{\text {mat, thermoelastic }}=\frac{q_{c}\left(T_{c}\right)}{w_{+}\left(T_{h}\right)-w_{-}\left(T_{c}\right)}=\frac{T_{c} \Delta s-A}{\left(T_{h}-T_{c}\right) \Delta s+2 A}$

$C O P_{\text {mat,magnetocaloric }}=\frac{q_{c}}{w_{n e t}}=\frac{T_{c} \Delta s-A_{\text {magnet }}}{\left(T_{h}-T_{c}\right) \Delta s+2 A_{\text {magnet }}}$

$$
C O P_{\text {mat, electrocaloric }}=\frac{q_{c}}{w_{\text {net }}}=\frac{T_{c} \Delta s-A_{\text {electrocaloric }}}{\left(T_{h}-T_{c}\right) \Delta s+2 A_{\text {electrocaloric }}}
$$

$$
C O P_{\text {mat,thermoelectric }}=\frac{q_{c}\left(I_{\text {opt }}\right)}{w_{\text {net }}\left(I_{\text {opt }}\right)}=\frac{T_{c}\left(\sqrt{1+Z T_{m}}-T_{h} / T_{c}\right)}{\left(T_{h}-T_{c}\right)\left(\sqrt{1+Z T_{m}}+1\right)}
$$

$C O P_{\text {mat }, \text { Brayton }}=\frac{q_{c}}{w_{\text {compressor }}-w_{\text {expander }}}=\frac{\left(h_{6}-h_{5}\right)_{P}}{\left[\left(h_{2}-h_{1}\right)_{s}-\left(h_{4}-h_{5}\right)_{s}\right]}$

$$
C O P_{\text {mat }, \text { Stirling }}=\frac{q_{c}\left(T_{c}\right)}{w_{+}\left(T_{h}\right)-w_{-}\left(T_{c}\right)}=\frac{T_{c}\left(s_{1}-s_{4}\right)}{T_{h}\left(s_{2}-s_{3}\right)-T_{c}\left(s_{1}-s_{4}\right)}
$$

Other thermal criteria have also been used widely in literature for different cooling technologies, each having its own unique advantages in describing the corresponding NIK technology, such as $Z T$ value (dimensionless figure-of-merit) for thermoelectric cooling and thermoionic cooling 
(Zhao and Tan, 2014), and relative cooling power $(R C P)$ for magnetocaloric cooling and elastocaloric cooling materials (Gschneidner and Pecharsky, 2000). However, these criteria cannot be applied universally for all NIK cooling technologies and therefore, are not used in this study.

Table 2 summarizes results from the materials comparison using the aforementioned two indices and the phase change temperature range. The operating temperature lift was chosen to be $10 \mathrm{~K}$ from $288 \mathrm{~K}\left(15^{\circ} \mathrm{C}\right)$ to $298 \mathrm{~K}\left(25^{\circ} \mathrm{C}\right)$ as the same basis for comparison, and enabling using Carnot COP as a metric to normalize. One can also choose the basis according to AHRI 210/240 standard (2008), if the target application is residential air-conditioners, or AHRI 550/590 (2003) for commercial building water chillers. Since not all NIK cooling technologies are mature enough to be operated under these two standards, and also as pointed out in the literature (Brown and Domanski, 2014, Bansal et al., 2012), niche markets may be more applicable for these NIK cooling technologies. As is demonstrated by the results, some NIK cooling technologies favor small temperature lift while others favor large temperature lifts. Thus, a medium temperature lift at $10 \mathrm{~K}$ is selected as a comparison standard. Figure 5 plots the results in Table 2, using both the $C O P_{\text {mat }}$ absolute values and the normalized $C O P_{\text {mat }}$ (or exergetic efficiency, second law efficiency) versus the non-dimensional latent heat. The liquid-vapor refrigerants dominate solid-state materials significantly. The range of non-dimensional latent heat spans more than one order of magnitude, which is consistent with the fact that mass based energy density is vastly different between solids and liquids. The solid-state materials can be divided into three groups: magnetocaloric materials with high $C O P$ but low latent heat (right-bottom corner), thermoelectric materials with low $C O P$ but relative high latent heat (left-top among solid-state materials), and medium $C O P$ and latent heat group (SMAs and electrocaloric cooling materials). 


\section{Comparison of Cooling Technologies}

The following conditions are used for performance comparison of all cooling technologies system, unless otherwise noted:

$T_{h}=293+0.5 \Delta T_{l i f t}[\mathrm{~K}]$

$T_{c}=293-0.5 \Delta T_{\text {lift }}[\mathrm{K}]$

$\Delta T_{\text {approach }}=5[\mathrm{~K}]$

$W_{\text {parasitic }}=0.2 W_{\text {cycle }, 20 \mathrm{~K}}$

We use a water-cooled water chiller as the same comparison basis, i.e. the heat sink water temperature is maintained at $T_{\mathrm{h}}$ specified in Eq. (20), and the heat source (cooling load side) water temperature is at $T_{\mathrm{c}}$ specified in Eq. (21). The approach temperature in Eq. (22) is used for any cooling technology requiring an additional heat exchanger for the water side. Figure 3 displays an arbitrary schematic of a vapor compression system as an example showing Eqs. (2022). The two streams of water are maintained at the specified temperature lift. The refrigerantwater heat exchangers, i.e. evaporator and condenser in this case, have the same approach temperature. Eq. (23) represents the assumption of a constant parasitic power consumption, which is equal to $20 \%$ of the driving system power (compressor power in Figure 3) when evaluated under $20 \mathrm{~K}$ temperature lift. This rough assumption should be updated when a better estimation or direct measurement of the parasitic power becomes available. One thing to notice is that the cooling capacity, heating capacity, and power consumption are varying with different system temperature lift, since the system components are all sized prior to changing the temperature lift.

\subsection{Vapor Compression Cooling (baseline)}

Figure 6 shows the normalized $C O P$ breakdown chart for the baseline vapor compression system (Radermacher and Hwang, 2005). The material hysteresis effect diminishes as the temperature lift increases, since the fraction of additional pressure, and therefore power requirement to induce 
evaporation and condensation is being reduced. The compressor isentropic efficiency loss and the expansion loss increase with pressure ratio of the compressor (or temperature lift). Here it is assumed that the compressor isentropic efficiency varies with the pressure drop and temperature lift following a specific correlation (Fang et al., 2014). The expansion loss decreases the efficiency by losing the expansion work and vaporizes part of the refrigerant as a result of deviation from the isentropic expansion process. The $60 \mathrm{kPa}$ pressure drop effect in both the condenser and the evaporator contributes to the third loss. The cost of approach temperature is that a higher internal temperature lift is needed to drive the external heat transfer between the refrigerant and the water loops in Figure 3. The parasitic power consumption reduces the overall system normalized $C O P$ to be 0.21 under $10 \mathrm{~K}$ temperature lift condition.

\subsection{Elastocaloric Cooling (Single Stage)}

Elastocaloric cooling (a.k.a. thermoelastic cooling) system uses latent heat associated with martensitic transformation in shape memory alloys (SMAs) (Qian et al., 2015b). This concept is under development since 2012 (Cui et al., 2012) and is still at a very early R\&D stage. There are a few groups conducting materials level studies developing higher latent heat SMAs, including Cu-Zn-Al (Manosa et al., 2009), Cu-Al-Ni (Chen et al., 2009), Cu-Al-Mn (Sutou et al., 2004), and the Ni-Ti (Tusek et al., 2015a). The reported system level study is very limited, and so far have all been based on Ni-Ti alloys. Schmidt et al. (2015) demonstrated a lab test facility without heat transfer fluid using $\mathrm{Ni}-\mathrm{Ti}$ ribbon under tensile mode, and was able to achieve $4 \mathrm{~K}$ internal temperature lift (metal heat sink-metal heat source). Qian et al. (2015c) developed the first compressive prototype using $\mathrm{Ni}-\mathrm{Ti}$ tubes, and reported maximum of $1.5 \mathrm{~K}$ water-water system temperature lift. A possible future design was following the active magnetocaloric regenerator, which was explored by a preliminary numerical study published recently (Tusek et al., 2015b).

Figure 7 shows the breakdown chart using the model developed by Qian et al. (2015b) and the improvements introduced by Qian et al. (2015d). The materials level hysteresis irreversibility 
limits the potential $C O P$ significantly in the low temperature lift range. Advances in new materials with high latent heat as well as smaller hysteresis, such as Ti-Ni-Cu, can help improve the efficiency of this cooling technology. The cycle proposed by Qian et al. (2015b) is operated under a single stage Brayton cycle, which could potentially be reduced by a more advanced cycle. The adiabatic compression irreversibility due to Brayton cycle was also reported by Tusek et al. (2015a) as the "temperature hysteresis" using a tension test rig. The mechanical driving system is assumed to have a $70 \%$ efficiency, contributing to the third loss. The heat recovery loss increases with increasing temperature lift, since more energy is wasted due to inefficient heat recovery at higher temperature lift, so does the cyclic loss caused by the cyclic temperature variation of any parasitic thermal mass in the system, i.e. metal supporting parts and part of the heat transfer fluid. Overall, the system normalized $C O P$ is 0.14 at $10 \mathrm{~K}$ temperature lift, and reaches its maximum at $17 \mathrm{~K}$.

\subsection{Magnetocaloric Cooling (AMR)}

Modern magnetocaloric cooling using an active magnetic regenerator (AMR) design has been developed rapidly in the past two decades. In the AMR, a magnetocaloric material is used as both the refrigerant and the regenerator. It can be reciprocating (Gomez et al., 2013) or rotary (Engelbrecht, 2008) in design and can consist of a plurality of regenerator beds. When a magnetocaloric material moves in the permanent magnet field, heat is generated during the magnetization process and is rejected by the heat transfer fluid. The material then absorbs heat when it is demagnetized. Recently, quite a few large scale AMR prototypes have been reported, including ones by Astronautics (Jacobs et al., 2014), Bahl et al. (2014), and Aprea et al. (2014). Both GE (2014) and Astronautics (2015) have announced launching timeline for magnetocaloric cooling products.

The materials level loss 1 for magnetocaloric materials are less than that of SMAs, as shown in Figure 8 . The next stage loss is predicted by the experimental validated AMR model, which was 
developed by Engelbrecht (2008). This loss 2 includes all of the internal irreversibilities inside the regenerator beds. It also takes in account the magnetic field reduction from 0-5 Tesla to the 01.5 Tesla to estimate the $C O P_{\text {mat }}$ in a real system. Loss 3 considers a $90 \%$ efficiency for the driving motor, and $70 \%$ efficiency for the high pressure pump to drive the AMR. The last loss factor is due to the external heat transfer loss. Ideally, the AMR itself uses water of other liquid as heat transfer fluid and no external heat transfer lost needs to be taken into account. Since AMR can only be operated under a relative small flow rate, we assume a $2 \mathrm{~K}$ temperature difference as an expense of small flow rate in both the cold- and hot-side. The normalized system COP of AMR system is 0.29 at $10 \mathrm{~K}$ temperature lift condition, which is higher than the baseline vapor compression systems. In addition, the AMR normalized COP reaches its maximum of 0.30 at $9 \mathrm{~K}$ temperature lift. Overall, advances in both magnetocaloric materials and permanent magnets to induce higher magnetic field, as well as highly efficient system integration are still needed. Major drawbacks in size, mass, pumping power, and especially the cost of the magnetocaloric materials are still challenges prohibiting its market penetration.

\subsection{Electrocaloric Cooling}

Electrocaloric cooling was also recently developed as one of NIK cooling technologies. When exposed to an electric field, electric (dipole) moments in the material become oriented and the entropy is reduced. This is similar to the magnetic field induced magnetic moments change in magnetocaloric materials (Ozbolt et al., 2014). Quite a few materials candidates have been developed so far, most of which are polymers or ceramics. P(VDF-TrFE) and P(VDF-TrFE-CFE) have shown superior latent heat to other materials (Moya et al., 2015).

One challenge for this technology, is the limitation in the shape of the materials. Only thin films can be applied since a high electric field is needed (hundreds of MV/m). Jia and Ju (2012) demonstrated a laboratory scale prototype using a multi-layer ceramic electrocaloric materials, and reported maximum of $1 \mathrm{~K}$ system temperature lift. Gu et al. (2013) reported a chip scale 
electrocaloric cooling prototype using solid-state external regenerator, and the maximum system temperature lift was almost $5 \mathrm{~K}$. Guo et al. (2014) developed a system model for an electrocaloric cooling system using heat transfer fluid. However, no power efficiency, parasitic pump power and other losses were reported. More studies on both materials level and system level are still needed to fully understand the potential for this NIK technology.

\subsection{Thermoelectric Cooling}

Thermoelectric cooling is a relatively mature NIK technology as compared with the aforementioned three solid-state cooling technologies. It is based on the Peltier effect, in which a temperature difference is generated by flowing current between two junctions of different materials. The dimensionless figure-of-merit, $Z T$, has been used to guide the materials development, which is around 1.0 for commercially available bulk materials (Zhao and Tan, 2014). The system integration for this NIK technology is much simpler than other NIK technologies, with no cyclic operation and no moving parts. Advances in materials development is the key to expand the applications from its niche market.

The $C O P_{\text {mat }}$ described by Eq. (17) already accounts for a few materials level irreversibility, i.e. additional voltage to compensate the resistance, parasitic heat generation by resistance, and parasitic heat conduction from the hot junction to the cold junction. This is the reason why the materials level COP is the lowest among all NIK technologies, as shown in Figure $9(Z T=1.4)$. The possible system integration loss is less than other NIK technologies. The external heat transfer loss caused by the water chiller approach temperature and the parasitic power consumption attributes to only 0.47 exergetic inefficiency, which places the $\Phi_{\text {sys }}$ of thermoelectric cooling at the top of the list.

\subsection{Stirling/Brayton Cooling Cycles}

Stirling refrigerators are mainly used for cryogenic applications in industry. The concept of Stirling cycle is old, and practically there were many modified cycles and machines built similar 
to the original concept. A good example is the Gifford-McMahon (G-M) cryocooler (McMahon and Gifford, 1960). Another heat activated version of a Stirling cooler is the Vuilleumier heat pump listed in Figure 1, which is driven by fuel heat to create cooling/heating based on a coupled Stirling engine and heat pump (Carlsen, 1989). Working fluid for Stirling refrigerators can be assumed to be an ideal gas under its working temperatures and pressures, including the most widely used helium, air, hydrogen, water, and sodium-potassium eutectic (Thombare and Verma, 2008). The major drawback of Stirling refrigerators is the complicated mechanical-thermal coupling design they required.

The model and the exergetic efficiency analysis developed by Razani et al. (2010) were used in this study. Figure 10 shows the breakdown chart for the Stirling cycle. As indicated in Table 2, there is no materials level loss by using the ideal gas laws. However, the first stage loss caused by the pressure drop across the regenerator severely reduces the exergetic efficiency, especially under the small temperature lift conditions, which is consistent with findings of the original study (Razani et al., 2010). The pressure ratio across the regenerator was assumed to be 0.8 based on that study. The second loss is due to the compressor and expansion efficiency, which were assumed to be 0.8 and 0.9 , respectively. The regenerator effectiveness, non-ideal phasing and external heat transfer contributes to the next stage loss. The regenerator effectiveness contribution is relatively small under low temperature lift conditions as compared to solid-state NIK technologies, since the non-dimensional latent heat for helium is much higher than those of solidstate refrigerants, according to Table 2. Another significant difference is the temperature lift associated with the maximum system normalized $C O P$. Helium under the Stirling cycle reaches the maximum system normalized $C O P$ of 0.15 at $64 \mathrm{~K}$.

With air as the refrigerant, Figure 11 presents the $C O P$ breakdown chart for Brayton cycle, following the model proposed by Ni et al., (1999) and assumes the compression ratio to be 3 . The first loss on the materials level, using the ideal gas equation-of-state, is caused by the additional 
temperature difference between the compressor discharge and the heat sink. If the application has a variable temperature heat sink and heat source such as a domestic hot water tank with a finite flow rate, the performance of a Brayton cycle would be significantly better. In addition, for higher temperature lift applications, the materials level normalized $C O P$ also increases, which reaches 0.6 around the temperature lift of $200 \mathrm{~K}$. Assuming the compressor efficiency of 0.8 , and expansion efficiency of 0.9 , the mechanical losses contribute to another significant portion of $C O P$ reduction. The overall trend is similar to that of a Stirling cycle. The maximum system normalized $C O P$ reaches its maximum of 0.15 at temperature lift of $130 \mathrm{~K}$.

\section{Discussions}

Table 3 summarizes the results from the previous two sections. The three left columns were evaluated under the temperature lift of $10 \mathrm{~K}$ as specified by Eqs. (20-21). The three right columns show the maximum $\Phi$ under their corresponding temperature lift conditions. It should be noted that theoretically it can be proved that a maximum system optimum $\Phi$ exist for any cooling systems. This is because of the following three facts.

(1) The Carnot COP under zero Kelvin temperature lift becomes infinite, and therefore any finite system loss contributes to a finite system $\mathrm{COP}$, corresponding to $\Phi=0$ under $0 \mathrm{~K} \Delta T_{\text {lift. }}$.

(2) Any realistic cooling system has a maximum system temperature lift due to the limited specific cooling or heating generated by all means. In other words, no realistic heat pump can approach the infinite $\Delta T_{\text {lift }}$ limit. Therefore, $\Phi$ becomes zero under the infinite $\Delta T_{\text {lift }}$ limit.

(3) Since the normalized system overall COP $\Phi$ is zero under both $0 \mathrm{~K}$ and infinite $\Delta T_{\text {lift, }}$, and it is a continuous function when varying the system temperature lift, it must have a maximum value when varying the temperature lift, according to the extreme value theorem (Larson and Edwards, 2012).

Based on the summary, the following observations can be deduced. 
The materials $C O P$ for magnetocaloric, electrocaloric, and elastocaloric increases monotonically with temperature lift, since the hysteresis irreversibility is a material constant. For vapor compression, however, the materials irreversibility is also effected by the "superheat horn" (Radermacher and Hwang, 2005), which also increases with the increasing temperature lift. Therefore, the vapor compression material exergetic efficiency has a peak at $37 \mathrm{~K}$ temperature lift. In terms of thermoelectric cooling, the parasitic heat loss from conduction scales linearly with the temperature lift, and therefore, it favors small temperature lift applications.

Since the evaporation-condensation process is highly reversible, only the magnetocaloric materials and ideal gas under a Stirling cycle are competitive to the baseline. Materials advances for elastocaloric cooling, electrocaloric cooling and thermoelectric cooling are desirable.

Thermoelectric cooling is simple to integrate on the system level, and the $\Phi_{\text {sys }}$ of thermoelectric cooling is the best among all evaluated NIK technologies.

The magnetocaloric cooling system is the only NIK technology superior to the baseline.

The four evaluated solid-state cooling technologies are only efficient under low temperature lift conditions, based on the last column in Table 3 (the temperature lift when the maximum normalized system COP is reached). Therefore, they would be better to be applied for small temperature lift applications, unless a high efficient cascaded system integration is realized.

Gaseous cycles are more efficient under high temperature lift conditions, as seen in the last column in Table 3. They have been used for cryogenic applications in the past. Significant modifications have to be made, in order to fit the small and moderate temperature lift applications with a better system efficiency.

Elastocaloric cooling has better potential due to higher latent heat when compared with other solid-state NIK technologies. More research effort are still needed to improve its system efficiency, such as a hybrid Stirling cycle or a regeneration design similar to AMR (Tusek et al., 
2015b). Both its $C O P_{\text {mat }}$ and the temperature lift for the maximum system normalized $C O P$ indicate the potential of elastocaloric cooling to become competitive for small and medium temperature lift applications.

More system integration research are urgently needed to assess the system level performance of electrocaloric cooling. Materials advances are also needed to reduce the hysteresis and enhance the latent heat.

As mentioned earlier, all the results discussed in this paper are for fixed size cooling systems, which implies that the cooling/heating capacity vary with system temperature lift. With the variable speed motor to adjust the driving system's capacity, the cooling/heating capacity could be potentially controlled to maintain constant under various system temperature lift conditions. This requires future work to address the losses associated with the variable speed driving system.

\section{Conclusions}

The $C O P$ breakdown analysis method was proposed in this study as a quantitative comparison for NIK cooling technologies. First, comparing the materials level performance for each NIK refrigerants using only the materials properties under the specified cycle path provides insight on the limit for each NIK technologies assuming the system can be ideal. Then the system integration losses were taken into account for the same operating conditions for a fair comparison. It was found that from both the materials and the system perspective, magnetocaloric cooling is so far the only NIK technology better than the vapor compression cooling. The four evaluated solid-state NIK technologies are more beneficial for small temperature lift applications, among which the elastocaloric cooling could be potentially applicable for a wider temperature lift range with advances in both materials and system integration. The evaluated two gaseous NIK technologies are superior in high temperature lift applications, and efforts in major components 
modifications are needed to increase their performance if medium temperature lift applications are required.

\section{Acknowledgment}

The authors gratefully acknowledge the support from the U.S. DOE (ARPA-E DEAR0000131) and the Center for Environmental Energy Engineering (CEEE) at the University of Maryland. This work was also supported by the GDF-Suez Chuck Edwards Memorial Fellowship (20142015).

\section{References}

AHRI 210/240, 2008. Performance rating of unitary air-conditioning and air-source heat pump equipment.

AHRI 550/590, 2003. Standard for performance rating of water-chilling packages using the vapor compression cycle.

Aprea, C., Greco, A., Maiorino, A., Mastrullo, R., Tura, A., 2014. Initial experimental results from a rotary permanent magnet magnetic refrigerator. Int. J. Refrigeration 43, 111-122.

Astronautics, 2015. http://www.coolingpost.com/world-news/debut-for-magnetic-refrigerationwine-cooler/ (Retrieved on May 20 $\left.0^{\text {th }}, 2015\right)$

Bahl, C.R.H., Engelbrecht, K., Eriksen, D., Lozano, J.A., Bjork, R., Geyti, J., et al., 2014. Development and experimental results from a $1 \mathrm{~kW}$ prototype AMR. Int. J. Refrigeration $43,78-83$.

Bansal, P., Vineyard, E., Abdelaziz, O., 2011. Advances in household appliances - A review. Appl. Therm. Eng. 31, 3748-3760. 
Bansal, P., Vineyard, E., Abdelaziz, O., 2012. Status of not-in-kind refrigeration technologies for household space conditioning, water heating and food refrigeration. Int. J. Sust. Built Environ. 1, 85-101.

Bechtold, C., Chluba, C., Lima, R., Quandt, E., 2012. High cyclic stability of the elastocaloric effect in sputtered TiNiCu shape memory films. Appl. Phys. Lett. 101, 091903. DOI: 10.1063/1.4748307.

Brown, D.R., Fernandez, N., Dirks, J.A., Stout, T.B., 2010. The prospects of alternatives to vapor compression technology for space cooling and food refrigeration applications. Available online: $\quad$ http://www.pnl.gov/main/publications/external/technical reports/PNNL19259.pdf (Retrieved on May $17^{\text {th }}, 2015$ )

Brown, J.S., Domanski, P.A., 2014. Review of alternative cooling technologies. Appl. Therm. Eng. $\quad 64,252-262$.

Carey, V.P., 2008. Liquid-vapor phase-change phenomena ( $2^{\text {nd }}$ edition). CRC Press, New York.

Carlsen, H., 1989. Development of a gas fired Vuilleumier heat pump for residential heating. Energy Conversion Engineering Conference, IECEC 1989.

Chen, Y., Zhang, X., Dunand, D.C., Schuh, C.A., 2009. Shape memory and superelasticity in polycrystalline Cu-Al-Ni microwires. Appl. Phys. Lett. 95. DOI: 10.1063/1.3257372.

Cui, J., Wu, Y., Muehlbauer, J., Hwang, Y., Radermacher R., Fackler, S., et al., 2012. Demonstration of high efficiency elastocaloric cooling with large Delta T using NiTi wires. Appl. Phys. Lett. 101, 073904. DOI: 10.1063/1.4746257.

Defay, E., Crossley, S., KarNarayan, S., Moya, X., Mathur, N.D., 2013. The electrocaloric efficiency of ceramic and polymer films. Adv. Mater. 25, 3337-3342. 
Engelbrecht, K., 2008. A numerical model of an active magnetic regenerator refrigerator with experimental validation. PhD Dissertation, University of Wisconsin-Madison.

Fang, X., Cheng, W., Zhou, A., Xu, Y., 2015. Empirical models for efficiency and mass flow rate of centrifugal compressors. Int. J. Refrigeration 41, 190-199.

Fischer, S.K., Tomlinson, J.J., Hughes, P.J., 1994. Energy and global warming impacts of not-inkind and next generation CFC and HCFC alternatives. Available online: http://www.afeas.org/tewi/tewi-ii.pdf (Retrieved on May $\left.17^{\text {th }}, 2015\right)$

Fischer, S.K., Labinov, S., 2000. Not-in-kind technologies for residential and commercial unitary equipment. Available online: http://web.ornl.gov/ webworks/cpr/v823/rpt/106022.pdf (Retrieved on May $17^{\text {th }}, 2015$ )

GE, 2014. http://www.gereports.com/post/75911607449/not-your-average-fridge-magnet (Retrieved on May 20 ${ }^{\text {th }}, 2015$ )

Goetzler, W., Zogg, R., Young, J., Schmidt, J., 2012. Energy savings potential and RD\&D opportunities for residential building HVAC systems. Available online: http://energy.gov/sites/prod/files/2014/09/f18/residential_hvac_research_opportunities.pd f (Retrieved on May $\left.17^{\text {th }}, 2015\right)$

Goetzler, W., Zogg, R., Young, J., Johnson, C., 2014. Energy savings potential and RD\&D opportunities for non-vapor compression HVAC technologies. Available online: http://energy.gov/sites/prod/files/2014/03/f12/NonVapor\%20Compression\%20HVAC\%20Report.pdf (Retrieved on May 17 $7^{\text {th }}, 2015$ )

Gomez, J.R., Garcia, R.F., Catoira, A.D.M., Gomez, M.R., 2013. Magnetocaloric effect: A review of the thermodynamic cycles in magnetic refrigeration. Renew. Sust. Energ. Rev. $17,74-82$.

Gschneidner, K.A., Pecharsky, V.K., 2000. Magnetocaloric materials. Annu. Rev. Mater. Sci. 30, $387-429$. 
Gschneidner, K.A., Pecharsky, V.K., Tsokol, A.O., 2005. Recent developments in magnetocaloric materials. Rep. Prog. Phys. 68, 1479-1539.

Gschneidner, K.A., Pecharsky, V.K., 2008. Thirty years of near room temperature magnetic cooling: $\quad$ where we are today and future prospects. Int. J. Refrigeration 31: 945-961.

Gu, H., Qian, X., Li, X., Craven, B., Zhu, W., Cheng, A., et al., 2013. A chip scale electrocaloric effect based cooling device. Appl. Phys. Lett. 102, 122904. DOI: 10.1063/1.4799283.

Guo, D., Gao, J., Yu, Y., Santhanam, S., Slippey, A., Fedder, G.K., et al., 2014. Design and modeling of a fluid-based micro-scale electrocaloric refrigeration system. Int. J. Heat Mass Trans. 72, 559-564.

Haar, L., Gallagher, J.S., and Kell, G.S., 1984. NBS/NRC Steam Tables, Hemisphere Publishing Corp., New York.

Herms, C.J.L., Barbosa, J.R., 2012. Thermodynamic comparison of Peltier, Stirling, and vapor compression portable coolers. Appl. Energy 91, 51-58.

Jacobs, S., Auringer, J., Boeder, A., Chell, J., Komorowski, L., Leonard, J., et al., 2014. The performance of a large-scale rotary magnetic refrigerator. Int. J. Refrigeration 37, 84-91.

Jia, Y., Ju, Y.S., 2012. A solid-state refrigerator based on the electrocaloric effect. Appl. Phys.

Lett. $\quad 100,242901$. DOI: $10.1063 / 1.4729038$.

Kitanovski, A., Egolf, P.W., 2006. Thermodynamics of magnetic refrigeration. Int. J. Refrigeration 29, 3-21.

Larson, R., Edwards, B.H., 2012. Calculus (10 ${ }^{\text {th }}$ edition). South-Western Pub, USA.

Lemmon, E, 2003. Pseudo-Pure Fluid Equations of State for the Refrigerant Blends R-410A, R404A, R-507A, and R-407C. Int. J. Thermophysics. 24(4), 991-1006.

Liu, J., Krautz, M., Skokov, K., Woodcock, T.G., Gutfleisch, O., 2011. Systematic study of the microstructure, entropy change and adiabatic temperature change in optimized La-Fe-Si alloys. Acta Mater. 59, 3602-3611. 
Liu, P.F., Wang, J.L., Meng, X.J., Yang, J., Dkhil, B., Chu, J.H., 2010. Huge electrocaloric effect in Langmuir-Blodgett ferroelectric polymer thin films. New J. Phys. 12, 023035. DOI: $10.1088 / 1367-2630 / 12 / 2 / 023035$.

Manosa, L., Planes, A., Vives, E., 2009. The use of shape-memory alloys for mechanical refrigeneration. Funct. Mater. Lett. 2, 73-78.

McMahon, H.O., Gifford, W.E., 1960. A new low-temperature gas expansion cycle. Adv. Cryog. Eng. 5, 354-367.

Mischenoko, A.S., Zhang, Q., Scott, J.F., Whatmore, R.W., Mathur, N.D., 2006. Giant electrocaloric effect in thin-film PbZr0.95Ti0.05O3. Science 311, 1270-1271.

Moore J.D., Morrison, K., Perkins, G.K., Schlagel, D.L., Lograsso, T.A., Gschneidner, K.A., 2009. Metamagnetism seeded by nanostructural features of single-crystalline Gd5Si2Ge2. Adv. Mater. 21, 3780-3783.

Moran, M.J., Shapiro, H.N., Boettner, D.D., Bailey, M.B., 2011. Fundamentals of engineering thermodynamics ( $7^{\text {th }}$ edition). John Wiley and Sons, Inc. Hoboken, USA.

Moya, X., Defay, E., Volker, H., Mathur, N., 2015. Too cool to work. Nat. Phys. 11, 202-205. DOI: $10.1038 /$ nphys3271.

Neese, B., Chu, B., Lu, S.G., Wang, Y., Furman, E., Zhang, Q.M., 2008. Large electrocaloric effect in ferroelectric polymers near room temperature. Science 321, 821-823.

Ni, N., Chen, L., Wu, C., Sun, F., 1999. Performance analysis for endoreversible closed regenerated Brayton heat pump cycles. Energy Convers. Manage. 40, 393-406.

Ozbolt, M., Kitanovski, A., Tusek, J., Poredos, A., 2014. Electrocaloric refrigeration; thermodynamics, state of the art and future perspectives. Int. J. Refrigeration 40, 174-188. 
Qian, S., Ling, J., Muehlbauer, J., Hwang, Y., Radermacher, R., 2015a. Study on high efficient heat recovery cycle for solid-state cooling. Int. J. Refrigeration. 55, 102-119.

Qian, S., Ling, J., Hwang, Y., Radermacher, R., Takeuchi, I., 2015b. Thermodynamics cycle analysis of thermoelastic cooling and heat pump systems. Int. J. Refrigeration. http://dx.doi.org/10.1016/j.ijrefrig.2015.04.001 (in press), available online.

Qian, S., Wu, Y., Ling, J., Muehlbauer, J., Hwang, Y., Takeuchi, I., et al., 2015c. Design, development and testing of a compressive thermoelastic cooling system. International Congress of Refrigeration 2015, Japan.

Qian, S., Alabdulkarem, A., Ling, J., Muehlbauer, J., Hwang, Y., Radermacher, R., et al., 2015d. Performance enhancement of a compressive thermoelastic cooling system using multiobjective optimization and novel designs. Int. J. Refrigeration (in-press). DOI:10.1016/j.ijrefrig.2015.04.012

Radermacher, R., Hwang, Y., 2005. Vapor Compression Heat Pumps with Refrigerant Mixtures. Taylor and Francis, New York.

Razani, A., Dodson, C., Roberts, T., 2010. A model for exergy analysis and thermodynamic bounds of Stirling refrigerators. Cryogenics 50, 231-238.

Riffat, S.B., Ma, X., 2004. Improving the coefficient of performance of thermoelectric cooling systems: a review. Int. J. Energ. Res. 28, 753-768.

Schmidt, M., Schutze, A., Seelecke, S., 2015. Scientific test setup for investigation of shape memory alloy based elastocaloric cooling processes. Int. J. Refrigeration. DOI: 10.1016/j.ijrefrig.2015.03.001 (in press), available online.

Sutou, Y., Omori, T., Wang, J.J., Kainuma, R., Ishida, K., 2004. Characteristics of Cu-Al-Mnbased shape memory alloys and their applications. Mater. Sci. Eng. A 378: 278-282.

Thombare, D.G., Verma, S.K., 2008. Technological development in the Stirling cycle engines. Renew. Sust. Energ. Rev. 12, 1-38. 
TillnerRoth, R., Harms-Watzenberg, and Baehr, H.D., 1993. Eine neue Fundamentalgleichung fur Ammoniak. DKV-Tagungsbericht. 20, 167-181.

TillnerRoth, R., and Baehr, H.D., 1994. An International Standard Formulation for the Thermodynamic Properties of 1,1,1,2-Tetrafluoroethane (HFC-134a) for Temperatures from $170 \mathrm{~K}$ to $455 \mathrm{~K}$ and Pressures up to $70 \mathrm{MPa}$. J. Phys. Chem. Ref. Data. 23(5), 657729.

TillnerRoth, R., and Yokozeki, A., 1997. An international standard formulation for difluomethane (R32) for temperatures from the triple point at $136.34 \mathrm{~K}$ to $435 \mathrm{~K}$ and pressures up to 70 MPa. J. Phys. Chem. Ref. Data 26, 1273-1328.

Tishin, A.M., Spichkin, Y.I., 2003. The magnetocaloric effect and its applications. IOP Publishing Ltd, Bodmin.

Tritt, T.M., 2011. Thermoelectric phenomena, materials, and applications. Annu. Rev. Mater. Res. 41, 433-448.

Tusek, J., Engelbrecht, K., Mikkelsen, L.P., Pryds, N., 2015a. Elastocaloric effect of Ni-Ti wire for application in a cooling device. J. Appl. Phys. 117, 124901. DOI: 10.1063/1.4913878.

Tusek, J., Engelbrecht, K., Millan-Solsona, R., Manosa, L., Vives, E., Mikkelsen, L.P., et al., 2015b. The elastocaloric effect: a way to cool efficienctly. Adv. Energy Mater. DOI: 10.1002/aenm.201500361

Yamashita, O., Ochi, T., Odahara, H., 2009. Effect of the cooling rate on the thermoelectric properties of p-type $\mathrm{Bi} 0.25 \mathrm{Sb} 0.75 \mathrm{Te} 3$ and n-type $\mathrm{Bi} 2 \mathrm{Te} 0.94 \mathrm{Se} 0.06$ after melting in the bismuth-telluride system. Mater. Res. Bull. 44, 1352-1359.

Yan, A., Muller, K.H., Gutfleisch, O., 2008. Magnetocaloric effect in LaFe11.8-xCoxSi1.2 meltspun ribbons. J. Alloys Compd. 450, 18-21.

Zhao, D., Tan, G., 2014. A review of thermoelectric cooling: Materials, modeling and applications. Appl. Therm. Eng. 66, 15-24. 
Ziolkowski, 1993. Theoretical analysis of efficiency of shape memory alloy heat engines (based on constitutive models of pseudoelasticity). Mech. Mater. 16, 365-377.

\section{Appendix}

For the vapor compression cycle plotted in Figure 4 (a), the latent heat term in Eq. (4) is:

$$
L=h_{1}-h_{4}
$$

Therefore, Eq. (4) for vapor compression cooling becomes Eq. (5).

For both the elastocaloric cooling, the magnetocaloric cooling and electricaloric cooling, the latent heat term in Eq. (4) is:

$L=T_{c} \Delta s$

As a result, Eq. (6-8) can be obtained by substituting Eq. (A-2) into Eq. (4). The highlight of entropy change at $T_{\mathrm{c}}$ for magnetocaloric cooling is due to a strong temperature dependence of entropy change for those materials around Cuire temperature.

Thermoelectric cooling is the only NIK technology without a cycle. The denominator in Eq. (4) for thermoelectric cooling is changed to the parasitic heat conduction loss through the material. The physical meaning of Eq. (4) for thermoelectric cooling then becomes the ratio between the useful cooling and the parasitic heat loss due to conduction, which is similar to other NIK technologies. If this ratio is beyond 1, it means the generated cooling by Seebeck effect can afford the parasitic conduction heat loss. Otherwise, the thermoelectric material is functional.

$\gamma_{\text {thermoelectric }}=\frac{q_{c}}{q_{\text {cond }}}=\frac{\alpha I_{o p t} T_{c}}{k x \Delta T_{\text {lift }}}$

The optimum current, according to Riffat and Ma (2004), is as following: 


$$
I_{o p t}=\frac{\alpha \Delta T_{l i f t}}{R\left(\sqrt{1+Z T_{m}}-1\right)}
$$

Substituting Eq. (A-4) to Eq. (A-3) yields

$$
\gamma_{\text {thermoelectric }}=\frac{\alpha^{2} \Delta T_{\text {lift }} T_{c}}{k x \Delta T_{\text {lift }} \cdot R\left(\sqrt{1+Z T_{m}}-1\right)}=\frac{\alpha^{2} T_{c}}{k \rho\left(\sqrt{1+Z T_{m}}-1\right)}
$$

where $x$ is the characteristic length, defined as ratio between the cross section area and the height, i.e. $x=$ area $/ l$.

Recall the definition of the figure-of-merit, Z, defined in Eq. (A-6), we can get the final equation for thermoelectric cooling in Eq. (9).

$$
Z \equiv \frac{\alpha^{2}}{k \rho}
$$

For Brayton cycle, the cooling capacity is induced by the temperature difference between state 6 and state 5, and therefore the "latent heat" term in Eq. (4) should be replaced by the sensible heat during the cooling process:

$$
L=h_{5}-h_{6}
$$

Combining Eq. (A-7) and Eq. (4) results in Eq. (10) for Brayton cycle.

For Stirling cycle, the cooling capacity is the isothermal entropy change between state 1 and state 4, which is shown in the following equation.

$$
L=T_{c} \Delta s\left(T_{c}\right)=T_{c}\left(s_{1}-s_{4}\right)
$$

Combining Eq. (A-8) and Eq. (4) yields Eq. (11) for gaseous Stirling cycle.

The $C O P$ is a path dependent variable based on its physical definition, since both heat and work are determined by the path. It can be simplified to a state variable by using only the material properties, when assuming the material equation-of-state (so that the path are "pre-defined"). An 
example is the $C O P_{\text {mat }}$ for Stirling cycle when using the ideal gas equation-of-state, which yields the Carnot COP (Thombare and Verma, 2008).

For vapor compression cooling, Eq. (13) is well-defined using the evaporator capacity for the numerator, and the net work input for the denominator (Radermacher and Hwang, 2005). The hysteresis was considered by the fact that additional vacuum is needed to grow bubble in evaporator, and additional pressure is required to induce droplet growth during condensation. This pressure difference can be converted to the temperature difference between the heat source and the saturation temperature of refrigerant, as shown in Eq. (A-9), which was assumed to be 1 $\mathrm{K}$. The same temperature difference was assumed in the condenser.

$\Delta T=T_{c}-T_{s a t}\left(T_{c}\right)=1[\mathrm{~K}]$

Eq. (14) was defined in (Qian et al., 2015b) based on a phenomenological model for SMAs. The material constant $A$ can be retrieved based on material stress-strain measurement data. Most literatures reported the isothermal loading-unloading curves on the stress-strain diagram, and some reported the adiabatic loading-unloading curves (Cui et al., 2012). The following two equations can be used to determine the material constant $A$.

$$
\begin{aligned}
& A=\frac{\left(\int_{0}^{\varepsilon_{\max }} \sigma_{l d} d \varepsilon-\int_{0}^{\varepsilon_{\max }} \sigma_{u l d} d \varepsilon\right)}{2 \rho} \text { where } \rho \text { is density }\left[\mathrm{kg} \cdot \mathrm{m}^{-3}\right] \text { for isothermal } \\
& A=\frac{\left(\int_{0}^{\varepsilon_{\max }} \sigma_{l d} d \varepsilon-\int_{0}^{\varepsilon_{\max }} \sigma_{u l d} d \varepsilon\right)}{2 \rho}-\frac{\Delta T_{a d} \cdot \Delta s}{2} \text { for adiabatic }
\end{aligned}
$$

Eq. (15) was defined following the same method with the SMAs, with the analogy from the stress-strain hysteresis to the field-magnetization hysteresis. It was assumed that the fieldmagnetization magnetization and demagnetization curves follow the ideal linear assumptions as 
graphically shown in Figure 4 (d). The magnetization hysteresis $A_{\text {magnet }}$ can be associated with the surrounded area of the isothermal curve under the same temperature.

$$
A_{\text {magnet }}=\left(\int_{m_{\min }}^{m_{\max }} \mu_{0} H_{\text {magnet }} d m-\int_{m_{\min }}^{m_{\max }} \mu_{0} H_{\text {demagnet }} d m\right) / 2
$$

The denominator in Eq. (15) can be derived in Eq. (A-13) using the graphical interpretation of Figure $4(\mathrm{~d})$. The surrounded area of the magnetization and demagnetization processes under the two temperatures is the net work for the magnetocaloric Ericsson cycle, including the hysteresis already. The third step simplification used the variant of the Clausius-Clapeyron equation under the equilibrium condition in Eq. (A-15), which is derived from its original format in Eq. (A-14) (Gshneidner and Pecharsky, 2005). The cooling is calculated in Eq. (A-16).

$$
\begin{aligned}
w_{\text {magnet }}-w_{\text {demagnet }} & =\left[H\left(T_{h}\right)-H\left(T_{c}\right)+\Delta H_{\text {hysteresis }}\right] \cdot \Delta m \\
& =\left[H\left(T_{h}\right)-H\left(T_{c}\right)\right] \cdot \Delta m+2 A_{\text {magnet }} \\
& =\left(T_{h}-T_{c}\right) \Delta s+2 A_{\text {magnet }}
\end{aligned}
$$

$\left(\frac{d H}{d T}\right)_{e q}=\frac{\Delta s}{\Delta m}$

$\frac{H\left(T_{h}\right)-H\left(T_{c}\right)}{T_{h}-T_{c}}=\frac{\Delta s}{\Delta m}$

$q_{c}=T_{c} \Delta s-A_{\text {magnet }}$

All the equations here are based on the results obtained for SMA using the linear phenomenological model proposed by Ziolkowski (1993). The method proposed here is an engineering simplification to compute the work needed to drive a magnetocaloric cooling cycle on the material level under various operating conditions. Direct experimental measures are more accurate, but have difficulty in estimating work under conditions other than the tested ones. 
The same method can be applied to electrocaloric cooling as well. The electrocaloric hysteresis can be calculated using the measured $D-E$ diagram, as shown in Eq. (A-17). Polarization $P-E$ diagram can be converted using Eq. (A-17).

$$
\begin{aligned}
& A_{\text {electrocaloric }}=\frac{\int_{0}^{D_{\max }} E_{l d} d D-\int_{0}^{D_{\max }} E_{u l d} d D}{2 \rho} \\
& D=P+\varepsilon_{0} E
\end{aligned}
$$

where $\varepsilon_{0}$ is the vacuum permittivity constant $\left(8.854 \times 10^{-12} \mathrm{~F} \cdot \mathrm{m}^{-1}\right)$.

Eq. (17) is directly used from Riffat and Ma (2004).

Eq. (18) and Eq. (19) are also straightforward using the cycle diagram in Figure 4. 


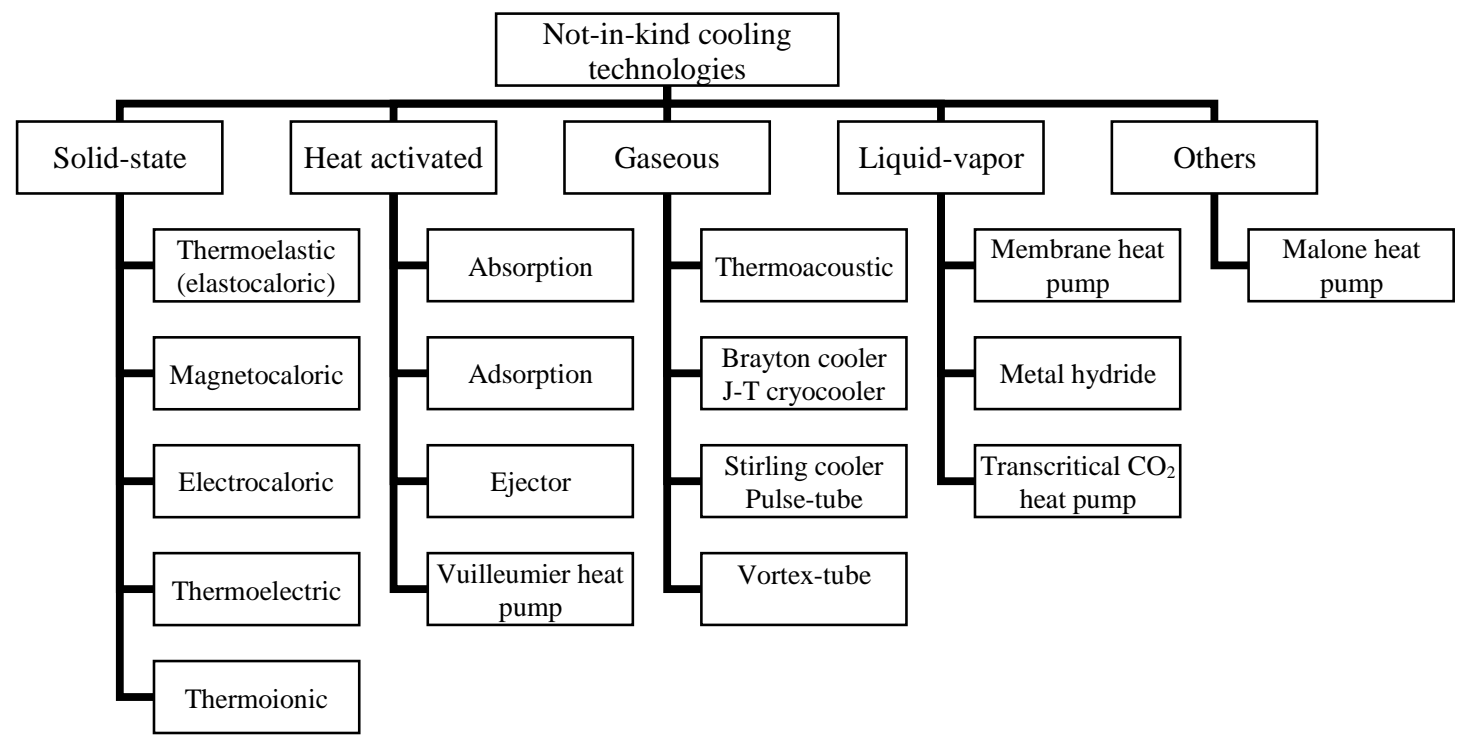

Figure 1: Various categories of not-in-kind cooling technologies. 

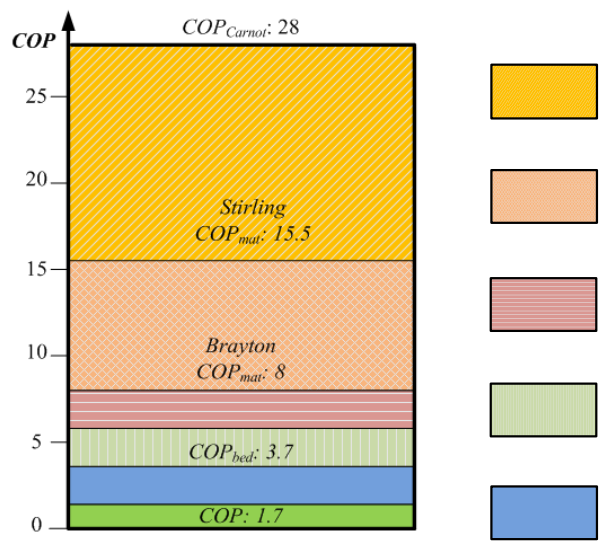

1. Irreversible Martensitic phase change losses (hysteresis)

2. Adiabatic compression loss

3. Mechanical losses due to motor efficiency $\eta_{\text {mot }}$ and work recovery efficiency $\eta_{\text {rec }}$

4. Heat transfer losses for solid-state refrigerant only, due to effectiveness $\varepsilon$ and heat recovery efficiency $\eta_{\mathrm{HR}}$

5. Cyclic losses and pump work

Figure 2: Methodology preview as an example used for elastocaloric cooling proposed in a previous study (Qian et al., 2015b, under $10 \mathrm{~K}$ temperature lift from $288 \mathrm{~K}$ to $298 \mathrm{~K}$ ). 




Figure 3: Illustration of common features for all cooling technologies using vapor compression cooling as an example. 

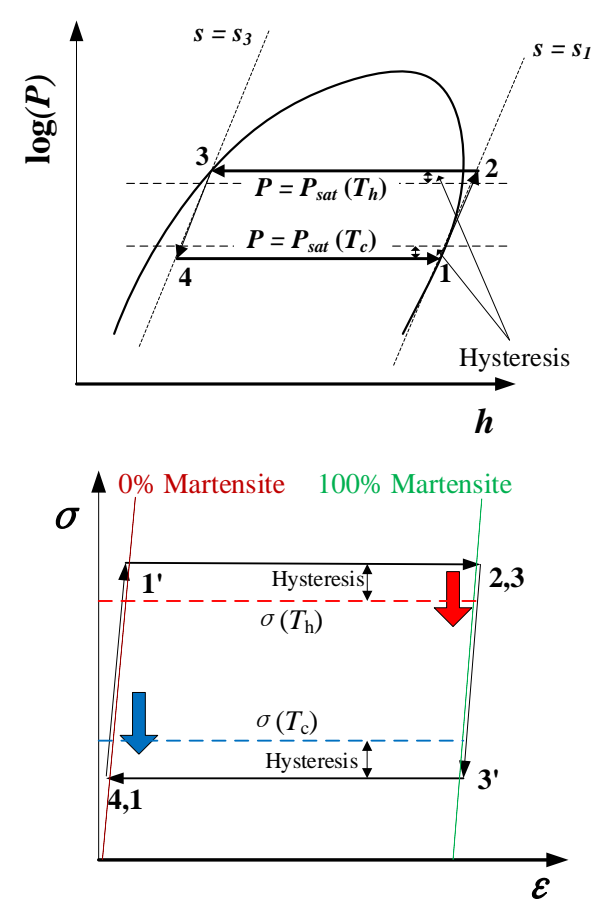

(b) Elastocaloric Stirling cooling cycle on a $\sigma$ $\varepsilon$ diagram

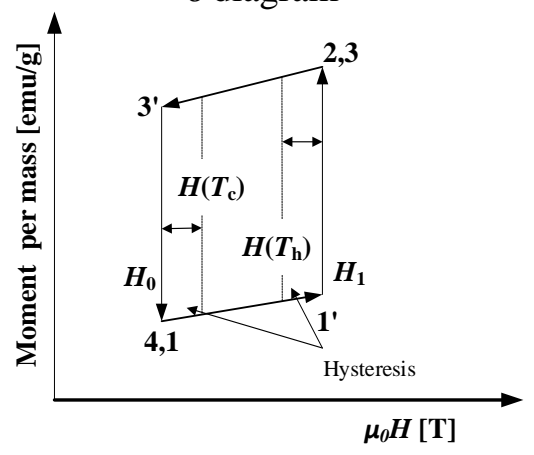

(d) Magnetocaloric Ericsson cooling cycle on a moment-field diagram

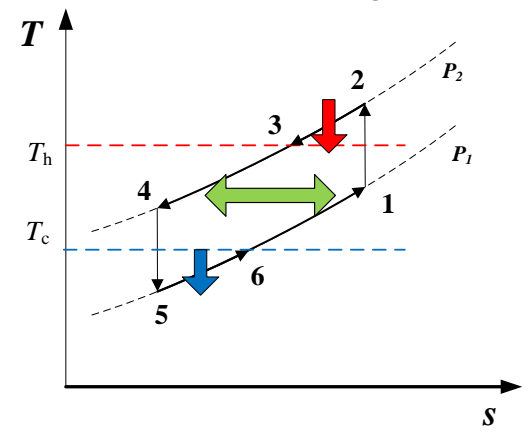

(f) Brayton cooling cycle on a $T-s$ diagram (a) Vapor compression cycle on a $P$ - $h$ diagram. State 1 is saturated vapor. State 3 is saturated liquid. Process from state 1 to 2 is isentropic compression. Process from state 3 to 4 is isentropic. No suction-line heat exchanger is applied here since there is no benefit for most refrigerants on the material level.

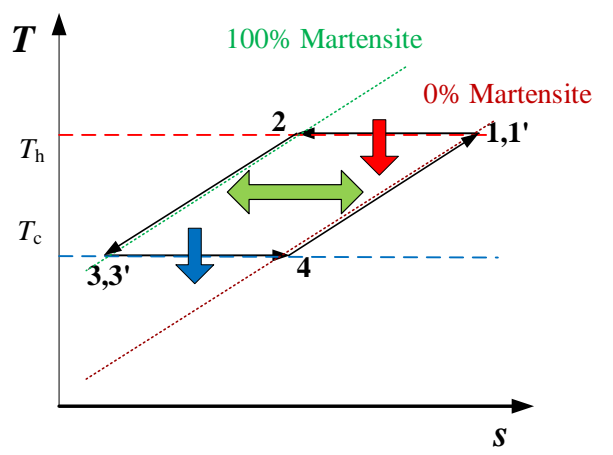

(c) Elastocaloric Stirling cooling cycle on a $T$ $s$ diagram

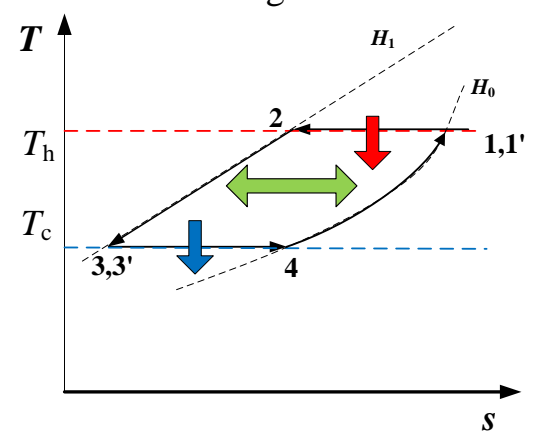

(e) Magnetocaloric Ericsson cooling cycle on

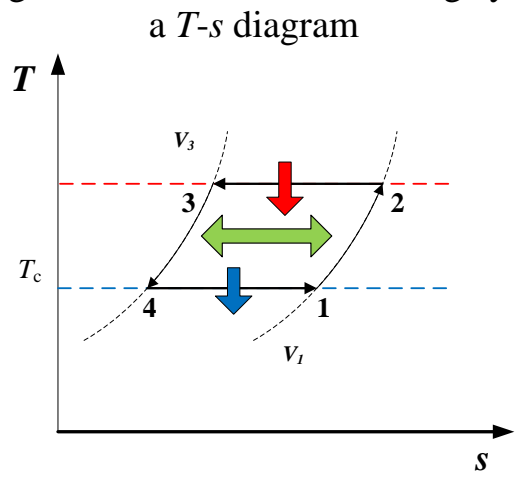

(g) Stirling cooling cycle on a $T$-s diagram

Figure 4: Ideal cycle description of different cooling technologies. 


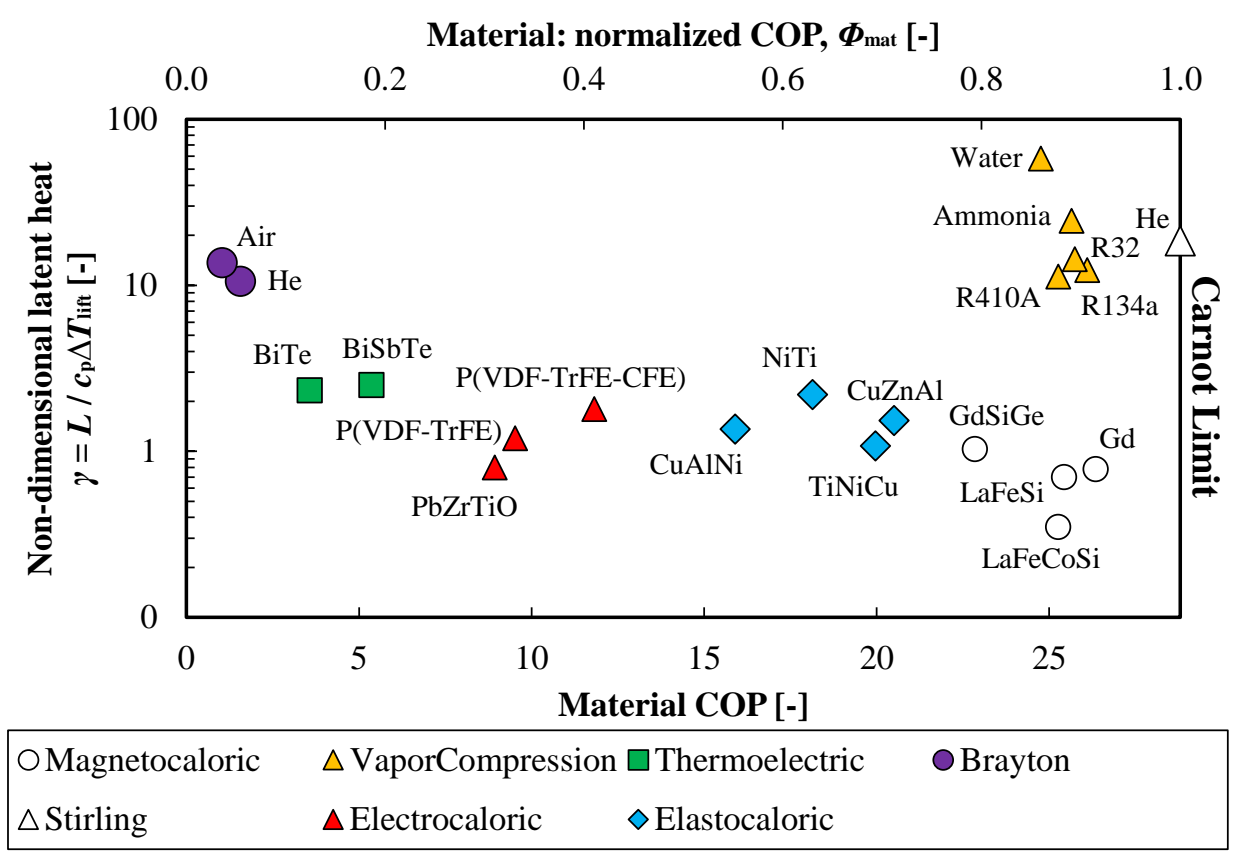

Figure 5: Comparison of the materials/refrigerants of various cooling technologies on the $C O P_{\text {mat }}$ and non-dimensional latent heat diagram $\left(T_{\mathrm{c}}=288 \mathrm{~K}, T_{\mathrm{h}}=298 \mathrm{~K}\right.$, Carnot $C O P=$ 28.8). 


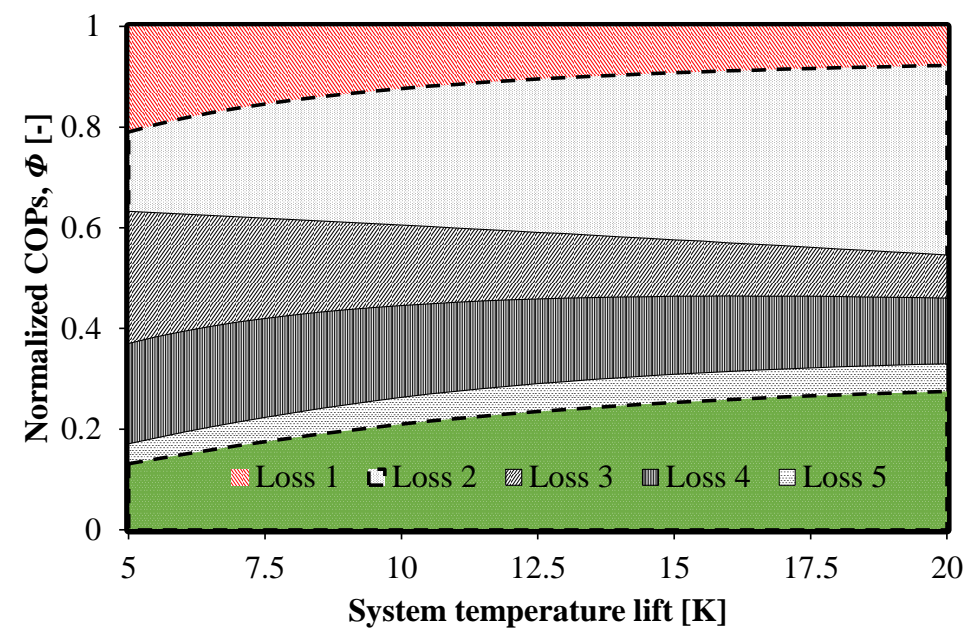

Loss 1: material hysteresis

Loss 2: compressor efficiency and expansion loss

Loss 3: pressure drop in two heat exchangers

Loss 4: external heat transfer irreversibility

Loss 5: parasitic power (pump, fan, etc.)

Figure 6: Loss analysis chart for the vapor compression cooling system. 


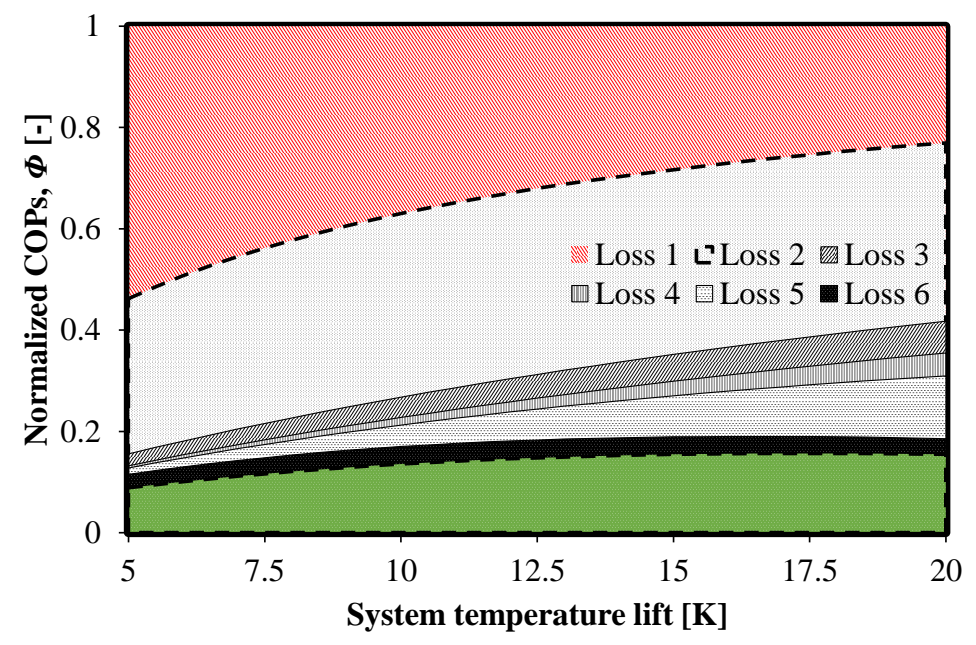

Loss 1: material hysteresis

Loss 2: adiabatic compression irreversibility

Loss 3: mechanical system efficiency

Loss 4: heat transfer and heat recovery/regeneration irreversibility

Loss 5: cyclic loss

Loss 6: parasitic power (pump, fan, etc.)

Figure 7: Loss analysis chart for the elastocaloric cooling system. 


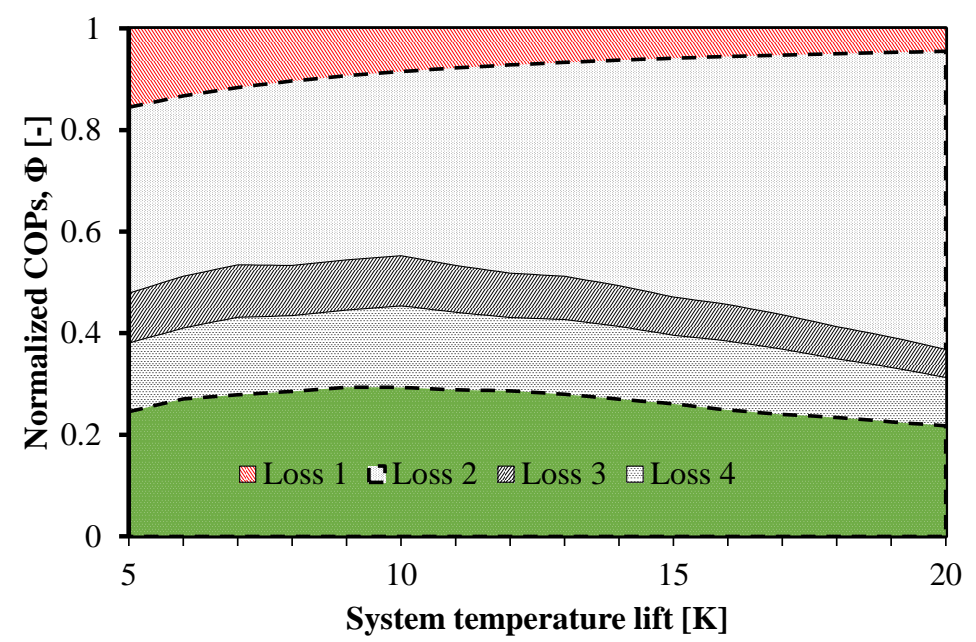

Loss 1: material hysteresis

Loss 2: AMR internal loss

Loss 3: parasitic power

(pump, motors)

Loss 4: external heat transfer irreversibility

Figure 8: Loss analysis chart for the AMR system. 


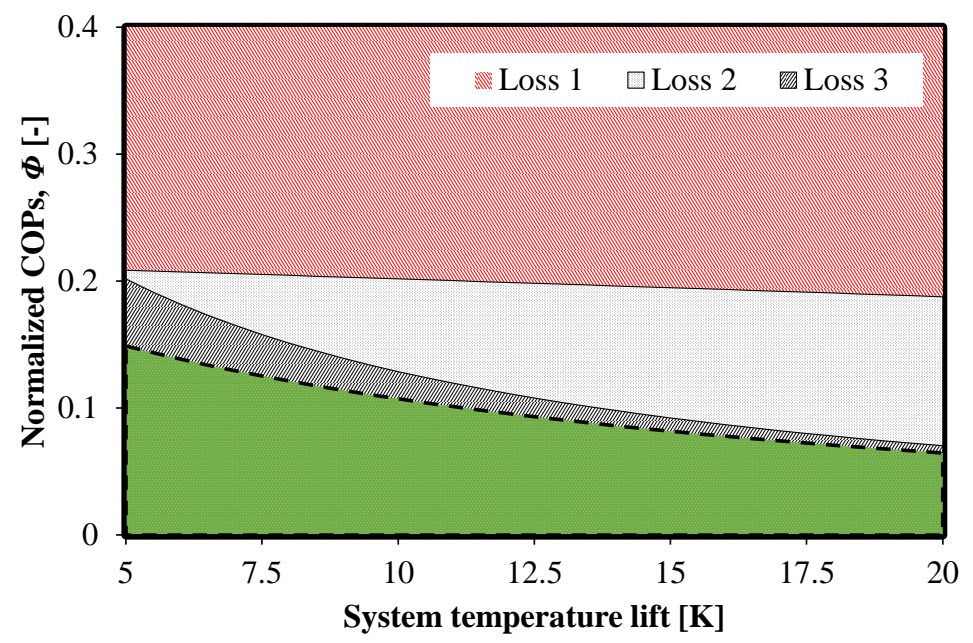

Loss 1: material hysteresis

Loss 2: external heat transfer irreversibility

Loss 3: parasitic power (pump, fan, etc.)

Figure 9: Loss analysis chart for the thermoelectric cooling system $(Z T=1.40$ for $\mathrm{Bi}-\mathrm{Sb}-\mathrm{Te})$. 


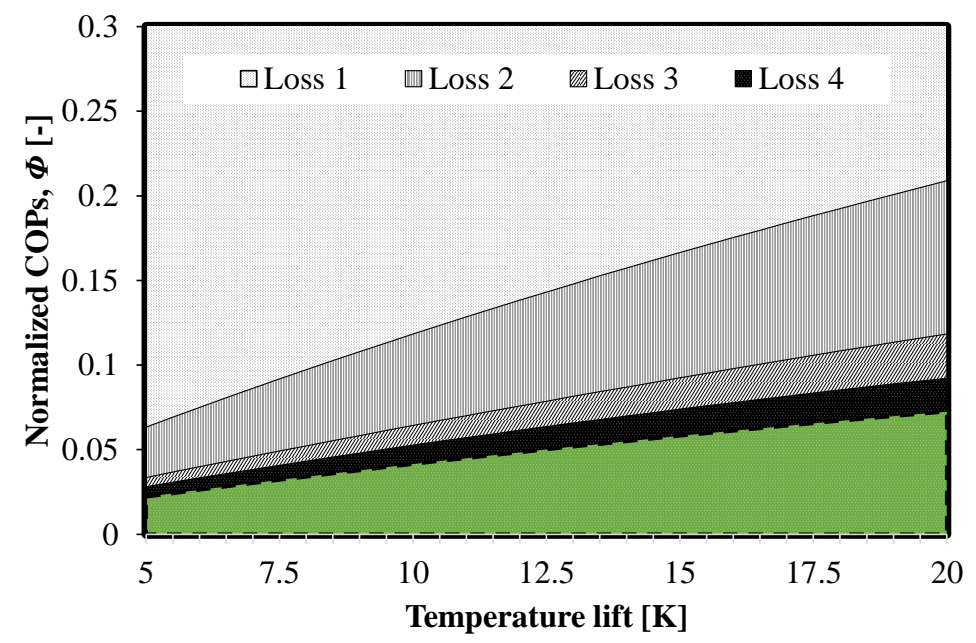

Loss 1: regenerator exergy loss due to pressure drop

Loss 2: compressor/expander efficiency

Loss 3: regenerator, phase and external heat transfer irreversibility

Loss 4: parasitic power (pump, fan, etc.)

Figure 10: Loss analysis chart for the Stirling cycle. 


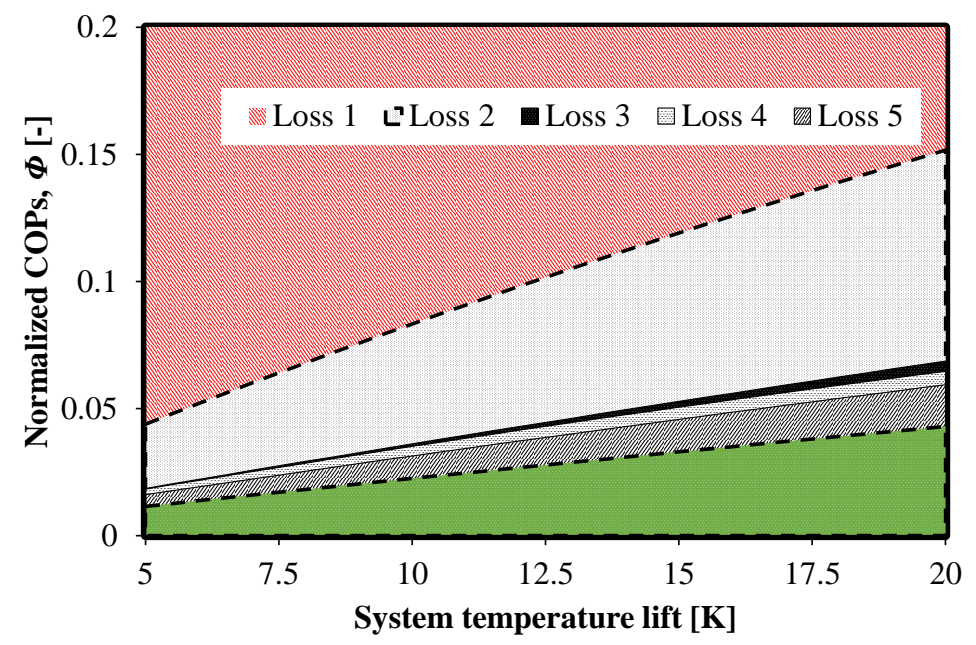

Loss 1: "superheat horn"

Loss 2: compressor and expander efficiency

Loss 3: regenerator loss

Loss 4: external heat transfer irreversibility and pressure drop

Loss 5: parasitic power (pump, fan, etc.)

Figure 11: Loss analysis chart for the Brayton cycle. 


\section{List of Figure Captions}

Figure 1: Various categories of not-in-kind cooling technologies.

Figure 2: Methodology preview as an example used for elastocaloric cooling proposed in a previous study (Qian et al., 2015b, under $10 \mathrm{~K}$ temperature lift from $288 \mathrm{~K}$ to $298 \mathrm{~K}$ ).

Figure 3: Illustration of common features for all cooling technologies using vapor compression cooling as an example.

Figure 4: Ideal cycle description of different cooling technologies.

Figure 5: Comparison of the materials/refrigerants of various cooling technologies on the $C O P_{\text {mat }}$ and non-dimensional latent heat diagram $\left(T_{\mathrm{c}}=288 \mathrm{~K}, T_{\mathrm{h}}=298 \mathrm{~K}\right.$, Carnot $\left.C O P=28.8\right)$.

Figure 6: Loss analysis chart for the vapor compression cooling system.

Figure 7: Loss analysis chart for the elastocaloric cooling system.

Figure 8: Loss analysis chart for the AMR system.

Figure 9: Loss analysis chart for the thermoelectric cooling system ( $Z T=1.40$ for $\mathrm{Bi}-\mathrm{Sb}-\mathrm{Te})$.

Figure 10: Loss analysis chart for the Stirling cycle.

Figure 11: Loss analysis chart for the Brayton cycle. 
Table 1: Brief summary of the NIK cooling technologies in this study.

\begin{tabular}{|c|c|c|c|c|c|c|c|}
\hline Technology & R\&D status $(*)$ & $\begin{array}{c}\text { Cost/complexity } \\
(*)\end{array}$ & Refrigerant & $\begin{array}{l}\text { Work } \\
\text { input } \\
\text { form }\end{array}$ & $\begin{array}{l}\text { Possible heat recovery } \\
\text { method }\end{array}$ & $\begin{array}{l}\text { Possible work } \\
\text { recovery method }\end{array}$ & Reference \\
\hline $\begin{array}{l}\text { Vapor } \\
\text { compression } \\
\text { (baseline) }\end{array}$ & Mature & Low & $\mathrm{R} 410 \mathrm{~A}$ & $\int p \mathrm{~d} v$ & $\begin{array}{l}\text { Suction-line heat } \\
\text { exchanger }\end{array}$ & Expander & $\begin{array}{l}\text { Radermacher and } \\
\text { Hwang, } 2005\end{array}$ \\
\hline Elastocaloric & R\&D, recently started & Moderate & $\mathrm{Ni}-\mathrm{Ti}$ & $\int \sigma \mathrm{d} \varepsilon$ & $\begin{array}{c}\text { Thermowave heat } \\
\text { recovery }\end{array}$ & $\begin{array}{c}\text { Multi-bed symmetric } \\
\text { design }\end{array}$ & Qian et al., 2015b \\
\hline Magnetocaloric & Advanced R\&D & High & Gd & $\int \mu_{0} H \mathrm{~d} m$ & $\begin{array}{l}\text { Active magnetic } \\
\text { regenerator }\end{array}$ & $\begin{array}{c}\text { Multi-bed rotary bed } \\
\text { design }\end{array}$ & Jacobs et al., 2014 \\
\hline Electrocaloric & $\mathrm{R} \& \mathrm{D}$, recently started & Moderate & $\begin{array}{c}\text { P(VDF- } \\
\text { TrFE-CFE) }\end{array}$ & $\int E \mathrm{~d} D$ & $\begin{array}{l}\text { Passive external } \\
\text { regenerator }\end{array}$ & $\mathrm{n} / \mathrm{a}$ & Gu et al., 2013 \\
\hline Thermoelectric & $\begin{array}{l}\text { Well established, on- } \\
\text { going materials } \\
\text { research }\end{array}$ & Moderate & $\mathrm{Bi}-\mathrm{Sb}-\mathrm{Te}$ & $\mathrm{n} / \mathrm{a}$ & $\mathrm{n} / \mathrm{a}$ & $\mathrm{n} / \mathrm{a}$ & Zhao and Tan, 2014 \\
\hline Stirling & Manufacturing issues & Moderate & Helium & $\int p \mathrm{~d} v$ & Regenerator & Piston & Razani et al., 2010 \\
\hline Brayton & Manufacturing issues & Moderate & Air & $\int p \mathrm{~d} v$ & $\begin{array}{l}\text { Recuperative heat } \\
\text { exchanger }\end{array}$ & Turbine & Ni et al., 1999 \\
\hline
\end{tabular}

*: based on Bansal et al., 2012 and Goetzeler et al., 2014 
Table 2: Materials/refrigerants comparison summary.

\begin{tabular}{|c|c|c|c|c|c|}
\hline Category & Refrigerant & $\begin{array}{l}\text { Phase change } \\
\text { temperature }[\mathrm{K}]\end{array}$ & $\gamma[-]$ & $\Phi_{\text {mat }}(*)$ & Reference \\
\hline \multirow{5}{*}{$\begin{array}{l}\text { Vapor } \\
\text { compression }\end{array}$} & Water & $273 \sim 647$ & 57.9 & 0.86 & Haar et al., 1984 \\
\hline & Ammonia & $195 \sim 405$ & 24.4 & 0.89 & TillnerRoth et al., 1993 \\
\hline & R32 & $136 \sim 351$ & 14.4 & 0.89 & $\begin{array}{l}\text { TillnerRoth and } \\
\text { Yokozeki, } 1997\end{array}$ \\
\hline & R134a & $172 \sim 374$ & 12.4 & 0.91 & $\begin{array}{l}\text { TillnerRoth and Baehr, } \\
1994\end{array}$ \\
\hline & R410A & $118 \sim 344$ & 11.3 & 0.88 & Lemmon, 2003 \\
\hline \multirow{4}{*}{ Elastocaloric } & $\mathrm{Ni}-\mathrm{Ti}$ & $73 \sim 373$ & 2.20 & 0.63 & $\begin{array}{c}\text { Cui et al., 2012, Tusek et } \\
\text { al., 2015a }\end{array}$ \\
\hline & $\mathrm{Cu}-\mathrm{Al}-\mathrm{Ni}$ & $73 \sim 387$ & 1.36 & 0.55 & Chen et al., 2009 \\
\hline & $\mathrm{Cu}-\mathrm{Zn}-\mathrm{Al}$ & $73 \sim 380$ & 1.53 & 0.71 & Manosa et al., 2009 \\
\hline & $\mathrm{Ti}-\mathrm{Ni}-\mathrm{Cu}$ & $300 \sim 345$ & 1.08 & 0.69 & Bechtold et al., 2012 \\
\hline \multirow{4}{*}{$\begin{array}{l}\text { Magnetocaloric } \\
(* *)\end{array}$} & $\mathrm{Gd}$ & $280 \sim 325$ & 0.78 & 0.91 & Tishin and Spichkin, 2003 \\
\hline & Gd-Si-Ge & $272 \sim 298$ & 1.03 & 0.79 & $\begin{array}{c}\text { Moore et al., 2009, } \\
\text { Gschneidner et al., 2005 }\end{array}$ \\
\hline & La-Fe-Si & $185 \sim 205$ & 0.70 & 0.88 & Liu et al., 2011 \\
\hline & La-Fe-Si-Co & $276 \sim 310$ & 0.35 & 0.88 & Yan et al., 2008 \\
\hline \multirow{3}{*}{ Electrocaloric } & $\mathrm{Pb}-\mathrm{Zr}-\mathrm{Ti}-\mathrm{O}$ & $323 \sim 553$ & 0.80 & 0.31 & Mischenoko et al., 2006 \\
\hline & $\mathrm{P}(\mathrm{VDF}-\mathrm{TrFE})$ & $303 \sim 383$ & 1.22 & 0.33 & Neese et al., 2008 \\
\hline & $\begin{array}{l}\text { P(VDF-TrFE- } \\
\text { CFE) }\end{array}$ & $300 \sim 350$ & 1.80 & 0.41 & Liu et al., 2010 \\
\hline \multirow{2}{*}{ Thermoelectric } & $\mathrm{Bi}-\mathrm{Te}$ & $200 \sim 600$ & 2.32 & 0.12 & Tritt, 2011 \\
\hline & $\mathrm{Bi}-\mathrm{Sb}-\mathrm{Te}$ & $200 \sim 600$ & 2.50 & 0.20 & Yamashita et al., 2009 \\
\hline \multirow[t]{2}{*}{ Brayton $(* * *)$} & Air & $77 \sim 400$ & 10.6 & 0.08 & \\
\hline & $\mathrm{He}$ & $4 \sim 400$ & 13.7 & 0.06 & Ideal gas \\
\hline Stirling & $\mathrm{He}$ & $4 \sim 400$ & 18.5 & 1.00 & \\
\hline
\end{tabular}

*: based on $T_{\mathrm{c}}=288 \mathrm{~K}$ and $T_{\mathrm{h}}=298 \mathrm{~K}$, Carnot $C O P$ is 28.8 .

$* *$ : based on $0 \sim 5 \mathrm{~T}$ data.

$* * *$ : based on pressure ratio of 3 . 
Table 3: Quantitative comparison of NIK cooling technologies.

\begin{tabular}{|c|c|c|c|c|c|c|}
\hline Technology & $\Phi_{\text {mat }}$ & $\begin{array}{r}\Phi_{\text {sys }} \\
\Delta T_{\text {lift }}\end{array}$ & $\begin{aligned} & \Phi_{\text {mat }} \cdot \Phi_{\text {sys }} \\
= & 10 \mathrm{~K}\end{aligned}$ & $\Phi_{\text {mat,max }} @ \Delta T_{\text {lift }}$ & $\Phi_{\text {sys,max }} @ \Delta T_{\text {lift }}$ & $\begin{array}{c}\left(\Phi_{\text {mat }} \cdot \Phi_{\text {sys }}\right)_{\max } @ \\
\Delta T_{\text {lift }}\end{array}$ \\
\hline $\begin{array}{l}\text { Vapor } \\
\text { compression } \\
\text { (baseline) }\end{array}$ & 0.88 & 0.23 & 0.20 & $0.94 @ 37 \mathrm{~K}$ & $0.30 @ 23 \mathrm{~K}$ & $0.27 @ 24 \mathrm{~K}$ \\
\hline $\begin{array}{l}\text { Elastocaloric } \\
\text { (single stage) }\end{array}$ & 0.63 & 0.21 & 0.14 & $1.00 @ \infty \mathrm{K}$ & $0.22 @ 13 \mathrm{~K}$ & $0.16 @ 17 \mathrm{~K}$ \\
\hline $\begin{array}{l}\text { Magnetocaloric } \\
\text { (AMR) }\end{array}$ & 0.91 & 0.32 & 0.29 & $1.00 @ \infty \mathrm{K}$ & $0.33 @ 9 \mathrm{~K}$ & $0.30 @ 9 \mathrm{~K}$ \\
\hline Electrocaloric & 0.41 & $\mathrm{n} / \mathrm{a}$ & $\mathrm{n} / \mathrm{a}$ & $1.00 @ \infty \mathrm{K}$ & $\mathrm{n} / \mathrm{a}$ & $\mathrm{n} / \mathrm{a}$ \\
\hline Thermoelectric & 0.20 & 0.53 & 0.13 & $0.21 @ 5 \mathrm{~K}$ & $0.70 @ 5 \mathrm{~K}$ & $0.15 @ 5 \mathrm{~K}$ \\
\hline Stirling & 1.00 & 0.04 & 0.04 & 1.00 & $0.12 @ 64 \mathrm{~K}$ & $0.12 @ 64 \mathrm{~K}$ \\
\hline Brayton & 0.08 & 0.27 & 0.02 & $1.00 @ \infty \mathrm{K}$ & $0.32 @ 82 \mathrm{~K}$ & $0.15 @ 130 \mathrm{~K}$ \\
\hline
\end{tabular}

